\title{
LUCES Y ARQUITECTURA EN LAS IGLESIAS COLONIALES DE LA NUEVA ESPAÑA Y DEL PERÚ
}

\author{
Lights and Architecture in the Colonial Churches of New Spain and Peru
}

\author{
Robert A. Benfer, Jr., Ph.D. ${ }^{1}$ \\ University of Missouri \\ benferr@missouri.edu
}

Fecha de recepción: 16-VI-2012

Fecha de aceptación: 31-XII-2012

\begin{abstract}
Resumen: En esta investigación, les presento los resultados de un estudio sobre las iglesias coloniales de Nueva España y el Perú, que muestran cuál fue el propósito de los primeros arquitectos. Estas construcciones fueron diseńadas de tal manera que los haces de luz, especialmente los procedentes de las ventanas de la cúpula, marcasen días de gran importancia astronómica y eclesiástica. La orientación de las iglesias variaba según las ciudades (que generalmente estaban alineadas con los puntos cardinales, normalmente de Este a Oeste) mientras que las misiones rurales estaban orientadas normalmente hacia los solsticios. En muchas ocasiones, la planeación de las ciudades seguía la orientación de las iglesias - aunque hay excepciones-, y algunos centros coloniales todavía conservan una orientación equinoccial o solsticial.

Hasta que Rubén Mendoza lo redescubrió en las misiones de California (2005, 2009), ni laicos y clérigos tenían noticia de este fenómeno. El trabajo que les presento aquí extiende su alcance desde las iglesias franciscanas de California hasta las de Texas de la misma orden, llegando también a las iglesias dominicas de México y Perú. Esta investigación muestra cómo el diseño de las iglesias coloniales está pensado para que la trayectoria de los rayos de luz marcara dentro de las iglesias el equinoccio, el solsticio y el día de cruce de cuartos (a mitad de camino entre los otros dos).
\end{abstract}

Palabras clave: arqueoastronomía; iglesias coloniales españolas; rayos de luz.

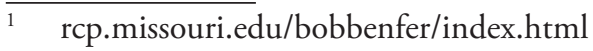


AвSTRACT: I present findings from study of Colonial Churches of New Spain and Perú that demonstrate the original architectects intent. The churchs were designed in such a manner that the play of lights, especially from dome windows, marked days of astronomical and ecclesiastical significance. General architectural orientations of churches varied with churchs in cities generally aligned to cardinal directions, especially east-west, while rural missions were often oriented towards solstices. City street plans often followed church orientations but not inevitably, and some Colonial city centers still reflect equinoctial or solsticial orientation.

The knowledge of these phenomena was lost to present day clergy and laity until Rubén Mendoza rediscovered them in California missions $(2005,2009)$. This work extends the range of these phenomena from the Franciscan churches of California to the Dominican churches of México, Franciscan churches of Texas, and Dominican churches of Perú. The work presented here shows the design of the Colonial churches causes them to produce beams of light whose path could mark the equinox, solstice, or cross-quarter day (the day midway between the two).

Keywords: Archaeoastronomy; Spanish Colonial Churches; Beams of Light.

\section{INTRODUCCION}

El eje longitudinal del edificio (Siglo VI, Iglesia de Santa Sofía, Constantinopla) coincide con la salida del sol en el solsticio de invierno de acuerdo con los cálculos antiguos, lo que implica que la orientación de la iglesia fue calculada con la intención de conseguir una iluminación natural en el interior. Los efectos luminosos y visuales sirvieron para reforzar el significado simbólico del espacio sagrado que además aportó evidencias acerca de las consideraciones ópticas con respecto a los conceptos antiguos de la luz y la visión (Schibille 2009, p. 27).

Guiar la luz mediante el diseño arquitectónico de las iglesias cristianas puede tener dos objetivos distintos. Por una parte, las entradas y ventanas de las iglesias pueden ser diseñadas para dejar entrar la luz en general; $y$, por otra, las iglesias pueden tener agujeros colocados en sitios específicos para producir, mediante los rayos, un efecto concreto además de la mera iluminación. Las iglesias más antiguas fueron diseńadas para manipular la luz con fines eclesiásticos y simbólicos. Más tarde, los científicos pudieron disponer de estos grandes espacios cerrados para medir con más precisión los recorridos del sol.

Heilbron (1999) estudió el uso de la luz solar en las iglesias europeas con fines científicos. En 1375, Toscanelli colocó un agujero en la linterna de la catedral de S. M. del Fiore con la intención de estudiar los cambios del eje de la tierra a través del tiempo en función de la trayectoria de la luz solar. Su trabajo se basó probablemente en los manuscritos clásicos griegos y árabes. En 1475, el astrónomo dominico Dante obtuvo la primera línea exitosa de los meridianos en las iglesias italianas abriendo un agujero en el techo de las mismas. Debido a las diferencias doctrinales, no fue hasta 1673 que 
se construyeron las líneas meridianas para la investigación astronómica (no eclesiástica) en Inglaterra (Amson 2008). Probablemente este conocimiento se había alcanzado ya antes en España. Como se verá, en las iglesias coloniales del Perú y la Nueva España los rayos de luz fueron dirigidos con fines astronómicos y eclesiásticos, para trazar hermosos senderos en el interior de las mismas. Estos haces de luz fueron diseñados para iluminar el pasillo, la entrada, las imágenes de los santos u otros objetos de la iglesia. Aunque la orientación de las iglesias en Europa ha sido ampliamente estudiada (McClusky 2007), el simbolismo eclesiástico de estas luces, reflejo del calendario natural, se ha perdido. El juego de esos rayos en las iglesias coloniales de hoy en día no produce más que irritación entre los feligreses y visitantes.

Las líneas proyectadas por los astrónomos con fines seculares en Europa fueron creadas a partir de agujeros específicos en el techo y, a veces, en las vidrieras, y se utilizaron para estudiar el equinoccio, la precesión, la altura del sol en el día del solsticio de verano, el movimiento anual de la Tierra, su oblicuidad y otros temas de interés astronómico. Más tarde, los agujeros en las catedrales fueron más precisos que los primeros e incluso algunos usaron telescopios para dirigir mejor la luz (Heilbron 1999: 225). Los avances en lentes telescópicas terminaron con las construcciones de estos agujeros con fines astronómicos en la década de 1820 . Hoy en día, sobreviven ejemplos europeos de perforaciones estratégicas en las iglesias que son de especial interés para los historiadores de la Iglesia Católica (por ejemplo, Heyd 2003). Pero no hay iglesias del Nuevo Mundo -en conocimiento del autor- que hayan sido modificadas con fines científicos. Sin embargo, según sostengo en este trabajo, el fenómeno de los haces de luz con una función simbólico-eclesiástica (que ha sido ya estudiado en Europa) tiene también una fuerte presencia en el continente americano.

Cualquier visitante que llegara a muchas de las iglesias coloniales de las Américas el día correcto estaría encantado de ver el espectáculo de luces diseñado con fines religiosos. En estas iglesias se puede comprobar que el conocimiento sistemático de la arquitectura y su relación con la astronomía se ha perdido. Es posible que esta pérdida esté relacionada con el final de la época colonial española, pero no he encontrado evidencia alguna a favor o en contra de esta hipótesis.

En las Américas, antes del sistemático trabajo de Mendoza (2005) y de la presente contribución, los haces de luz aislados fueron interpretados como medios para marcar fechas importantes del catolicismo (por ejemplo San Cristóbal 2000). Sin embargo los descubrimientos más recientes demuestran que muchas iglesias coloniales de la Nueva España y del Perú proyectan haces de luz en fechas importantes también para la astronomía. Mendoza presenta información sobre la relación entre la astronomía y el calendario católico que serán de ayuda para el lector a la hora de entender este artículo. Estas luces continúan dando un precioso espectáctulo en iglesias y misiones año tras año en 
días específicos con las últimas luces del sol y marcan el equinoccio, el solsticio, los días de cruce de curatos y otros días de interés (por ejemplo el Día de Todos los Santos o el Viacrucis, Mendoza, 2005)

En California, las ventanas de la misión iluminan algunos puntos de interés eclesiástico en un magnífico espectáculo de luces (Mendoza 2005: 2-5). Mendoza descubrió que las luces tenían una función de calendario astronómico en las misiones franciscanas de la frontera norte de la Nueva España -hoy California-y las asoció con la arquitectura funeraria y con la iconografía eclesiástica (2005). El autor sostiene que la adopción sincrética de Cristo-Sol todavía estaba presente en las misiones de finales del siglo XVIII y principios del XIX construidas por los franciscanos y por los Ohlone Casanoan -indios de California-. Las ventanas de la iglesia de Chiapas también fueron diseñadas para que proyectaran haces de luz sobre las imágenes que tenían un lugar especial en la iglesia o sobre otros objetivos de interés simbólico.

En este artículo me centraré en las líneas del equinoccio (meridiano), en las del solsticio, y en las de los días de la cruce de cuartos (entre el equinoccio y solsticio). La mayor parte de la investigación se centra en las iglesias de San Cristóbal de las Casas del Estado de Chiapas, además de otras ciudades como Lima, Perú, y San Antonio, Texas. Algunas misiones de Chiapas están en pueblos cuyas calles son orientadas de acuerdo a las direcciones intercardinales, importantes en la organización de asentamientos mayas como el de Cooapa, en la selva chiapaneca (Lee 1977). Dos de las iglesias más antiguas de Lima y una misión de principios del silgo XVIII de Texas también se destacan por sus luces en el solsticio. La orientación de la nave, en sí misma, ya es un indicio de la una posible manipulación de las luces en el interior. Las iglesias fueron a menudo orientadas al equinoccio en las ciudades y a los solsticios en el medio rural. La intención inicial de los arquitectos, ya fuera para celebrar fechas sagradas cristianas, indígenas o una combinación sincrética de ambas, aún no está clara. También presentaré algunos ejemplos de luces que iluminan importantes símbolos cristianos, como el tabernáculo o algunos santos de forma individual. Cuando la orientación de las iglesias y edificios relacionados sigue las direcciones intercardinales es normalmente por influencia indígena.

Inicié esta investigación en dos iglesias del siglo XVII: Santo Domingo y La Caridad; y dos del siglo XIX: Santa Lucía y Guadalupe, en San Cristóbal de las Casas, Chiapas, México (SCLC en adelante). Markman (1984) ya había descrito las iglesias de SCLC, pero no apreció la importancia astronómica que éstas tenían. Todas las fechas de estas iglesias se han tomado de Markman a menos que se indique lo contrario. Cabe señalar que sus dibujos no son siempre exactos con respecto a la orientación del norte magnético y los acimuts que presenta han sido tomados desde el altar hasta la entrada principal de la iglesia y no al revés, como sería preferible. 
La niebla y la lluvia son habituales en los Altos de Chiapas y con frecuencia hicieron imposibles mis observaciones de campo, especialmente durante la larga época de lluvias. A pesar de todo, durante las varias horas que el sol necesita para trazar el camino a lo largo del pasillo de una iglesia, había momentos de luz que a menudo se veían interrumpidos por las nubes. Estos saltos producían breves pero dramáticos espectáculos de luz.

\section{CHIAPAS: RAYOS DE LUZ EN LAS IGLESIAS COLONIALES}

En 2007, mi esposa sugirió que asistiéramos a una misa indígena de maya-tzeltales que se celebra en la iglesia indígena de La Caridad en SCLC, que data de princpios del siglo XVII (Fig. 1). Fue el 7 de febrero del año 2007. En la misa, me sorprendió ver una macha de luz que recorría de arriba abajo el retablo y cuando tuve conocimiento de los hallazgos de Mendoza en las misiones de California, decidí regresar para hacer un estudio más completo. Comencé en el año 2008 estudiando el trazado de las líneas de los meridianos en los pasillos de la iglesia como se hace en Europa.

El trazado de la línea del meridiano en la nave de una iglesia por medio de un rayo de luz en el día del equinoccio es un fenómeno impresionante. Para lograr esto, los arquitectos de la iglesia tuvieron que calcular este camino a través de las ventanas de la cúpula u otras ventanas de diferentes alturas, en iglesias cuyos pasillos difierían en la orientación. Desde las ventanas que estaban por encima del horizonte, los arquitectos tuvieron que calcular la posición del sol a lo largo de la trayectoria curva que traza en

Figura 1-Chiapas.

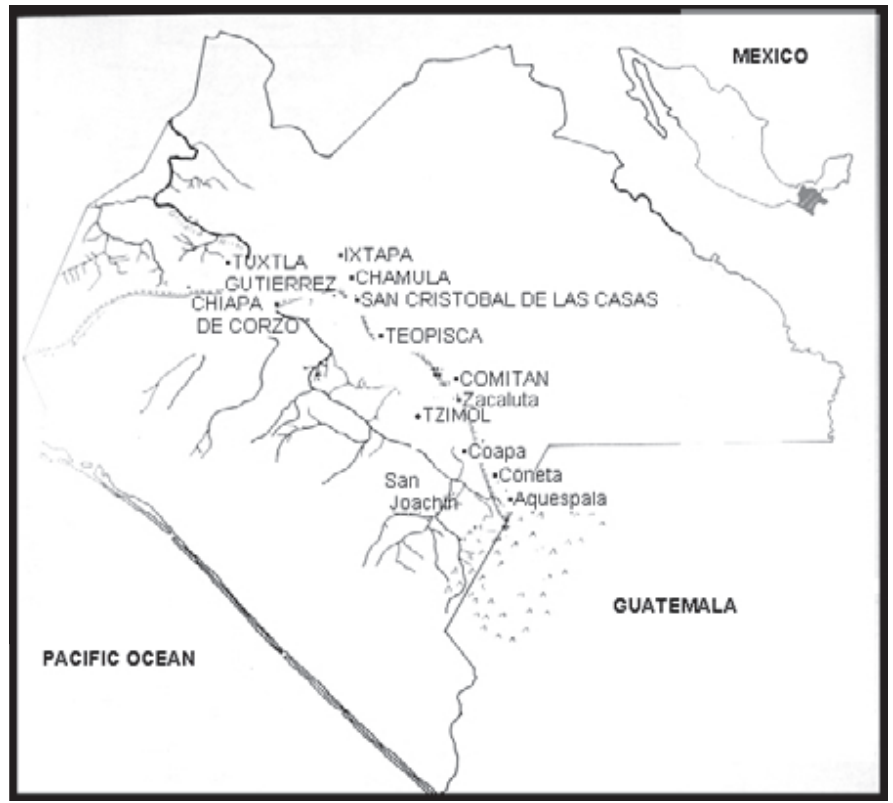


el cielo. El día del equinoccio de primavera, en marzo, la trayectoria de un rayo de luz recorre el centro del pasillo anunciando el día de Pascua. El día de Pascua es el primer domingo después de la primera luna llena en el que el sol se eleva a $90^{\circ}$ de acimut en un horizonte plano (en realidad, 89,5 debido a la refracción). Cuando se usan las iglesias como instrumentos de medición astronómica, la línea del meridiano sitúa los solsticios en los extremos y el equinoccio, en el centro.

En términos simples podríamos decir que en las construcciones que carecen de cúpulas, la entrada trasera de la iglesia podría dirigir la luz equinoccial a lo largo de un pasillo orientado de Este a Oeste. Pero en el caso de las ventanas situadas en ambos extremos del eje longitudinal de la iglesia, la nave tiene que estar construida en un acimut que no sea de Este a Oeste para que el sol trace una línea meridiana, dada la curvatura evidente del sol ascendente y descendente.

Las líneas de los meridianos de las iglesias europeas, adaptadas por los astrónomos con fines científicos son ampliamente conocidas (Heilbron 1999). Cuando comencé esta investigación, no se conocía ningún caso en las Américas salvo el de las misiones estudiadas por Mendoza.

Para mi sorpresa, encontré rayos de luz procedentes de las ventanas de la cúpula que se desplazaban desde la parte trasera del pasillo hasta la parte delantera el día del equinoccio en varias iglesias en SCLC. Las fechas de los solsticios y los días a mitad de camino entre el solsticio y el equinoccio, se añadieron posteriormente como días de interés para esta investigación. La metodología se ha beneficiado de la disponibilidad reciente de programas planetarios precisos y de las imágenes de Google Earth. El ajuste de la declinación también lo facilitó el uso de las calculadoras en línea.

\section{METODOLOGÍA}

La calculadora web NOAA corrige la declinación de los mapas antiguos que carecen de una flecha de norte verdadero. Google Earth Pro V. 5.2.1 fue utilizado en este trabajo para proporcionar los acimuts de los mapas que no los tenían o para contrastar los datos de los que sí. Estos datos astronómicos se ajustan a su ubicación, la cual se señala en la parte inferior de la foto de cada iglesia. La precesión es insignificante y la oblicuidad es de influencia muy pequeña en unos cuantos siglos, pero se hicieron las correcciones pertinentes. La salida del sol sobre el horizonte, digamos, en el equinoccio, es muy anterior a la aparición de un rayo de luz atravesando la ventana de la cúpula de una iglesia. La versión 5.01 de Starry Night Pro se utilizó para calcular los acimuts del sol al amanecer en diferentes altitudes, latitudes y fechas. También se hizo uso de una brújula de bolsillo (Brunton en adelante) para comprobar los datos proporcionados por Google Earth Pro. Cuando se repitieron las visitas para fotografiar y tomar medidas se 
hizo, siempre que fue posible, en las mismas fechas o en fechas cercanas. Las alineaciones astronómicas estudiadas fueron los solsticios, los equinoccios y los días de cruce de cuartos. Las coordenadas de las iglesias y de la ciudad se presentan como si hubieran sido tomadas de Google Earth Pro. Con pocas excepciones, la construcción de las iglesias estudiadas aquí data de la época colonial de México y de Nueva España.

Para empezar, se expondrán a continuación los resultados de la investigación realizada sobre las iglesias coloniales de SCLC.

\section{LUZ DEL EQUINOCCIO, SAN CRISTOBAL DE LAS CASAS}

La Caridad, SCLC (1644'27.23” N, 92³8'13.72” O). La iglesia de los dominicos de La Caridad de SCLC se construyó alrededor de 1560 NE. Antigás (1991) proporciona información interesante sobre esta iglesia, que está dedicada a San Juan de Dios. La brújula Brunton, situada en el suelo en el centro del pasillo lee $272^{\circ} 25^{\prime}$, lo cual corresponde con la lectura de Google Earth Pro de $272^{\circ}$. Esta iglesia fue construida en una fecha próxima a su vecina, Santo Domingo. En La Caridad, el altar está debajo de la cúpula principal mientras que en Santo Domingo está al frente de la misma. Markman (1984) presenta los planos de ésta y de las otras iglesias de las que se habla a continuación.

En 2008, en el equinoccio de primavera, la luz del suroeste de las cuatro ventanas de la cúpula de la capilla de La Caridad proyecta un rayo que se desplaza desde el punto medio del pasillo central de la iglesia hasta el altar. La figura 2 muestra los últimos 20 minutos de esa travesía, aunque la luz del sol se perdió antes de llegar al altar en este equinoccio de marzo. El equinoccio de primavera es el único día en el que el haz de luz procedente de la cúpula pasa cerca del centro del pasillo. Como muestra la Figura 2, el haz no esta centrado completamente pero el día del equinoccio es el único en el que está totalmente contenido en el pasillo.

Justo al oeste de La Caridad está la iglesia más grande, la de Santo Domingo, cuya construcción se inició alrededor de 1560: Santo Domingo de Guzmán, SCLC (164 $30.03^{\prime \prime}$ N 92³8'14.62” O). En el año 2008, el Domingo de Ramos fue cinco días antes del equinoccio. Yo estaba en la iglesia para ese oficio el día 16 de marzo con una cámara de fotos, una de vídeo y un trípode, sin saber realmente qué esperar. Un rayo de luz azul brillante procendente del suroeste de la cúpula apareció por primera vez en el extremo oeste del pasillo principal en la parte norte. Viajó por el lado norte de la nave hacia el Este y se detuvo frente a las escaleras del púlpito un poco antes de desaparecer.

Las imágenes tomadas una semana después de Pascua muestran un rayo de luz que avanza hacia el púlpito, pero a lo largo de las bancas del lado sur. Hay una breve 

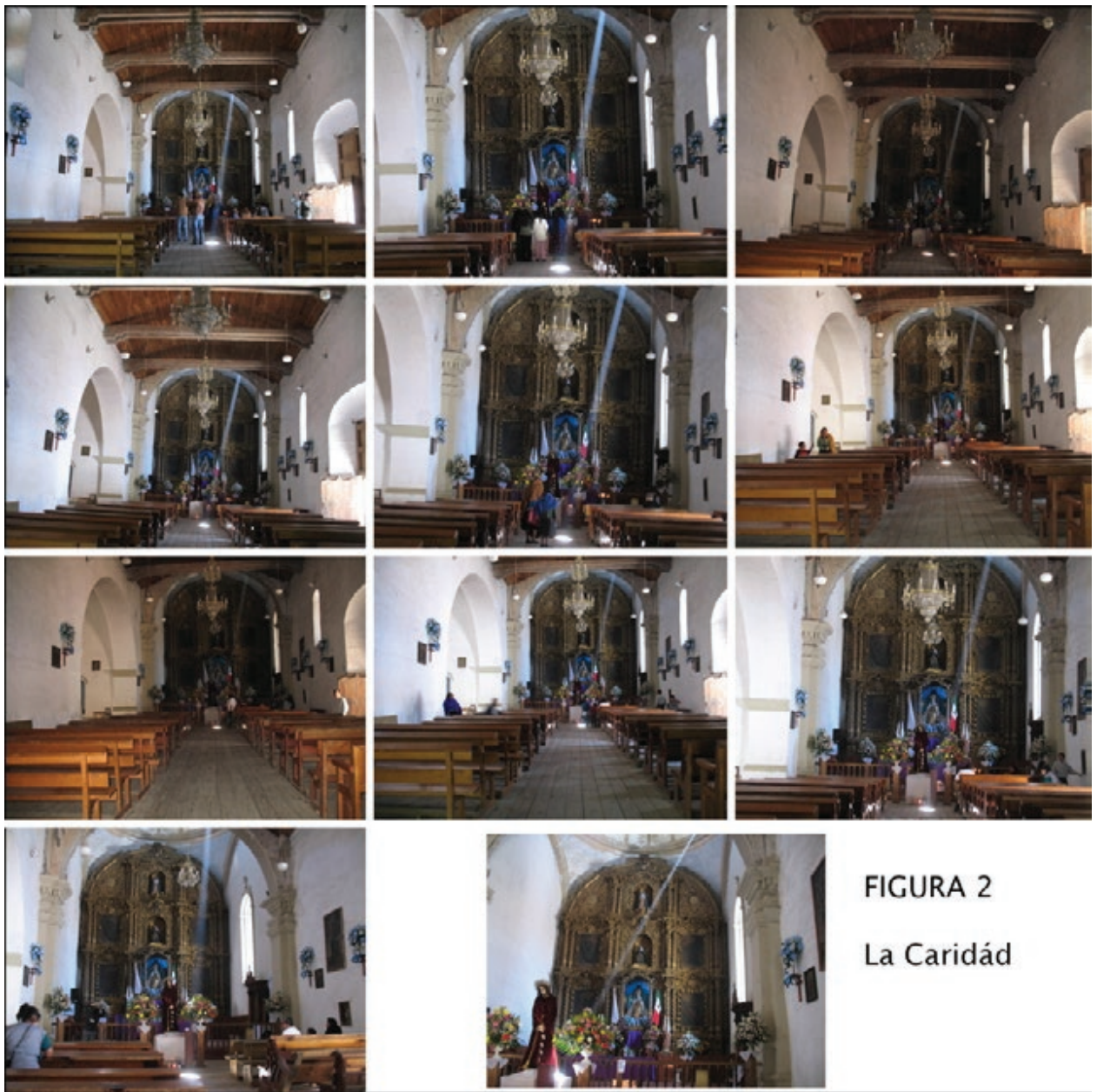

FIGURA 2

La Caridád

Figura 2-Movimiento del haz de luz procedente de la cúpula en el pasillo de La Caridad el día del equinoccio.

grabación disponible del Domingo de Ramos en esta iglesia: (<http://www.youtube. $\mathrm{com} /$ watch?v=xjsvAzOs8LM\&feature=mfu_in_order\&list=UL $>)$.

Las fotografías tomadas en el equinoccio de primavera del 2011 muestran que el haz de luz comienza en la parte trasera de la iglesia y avanza por el pasillo hasta las escaleras del púlpito (figura 3). Su posición está menos centrada que la de La Caridad, pero se mantiene dentro del pasillo el día del equinoccio. Las mediciones muestran que el pasillo se encuentra en el centro de la nave, pero no está orientado exactamente EsteOeste. La declinación corregida de éste mediante los acimuts de Brunton (colocado en el suelo en el centro del pasillo) es 271057’ mientras que Google Earth Pro dice que está a $271^{\circ}$. El rayo no puede seguir el pasillo porque éste no está orientado de Este a Oeste. 

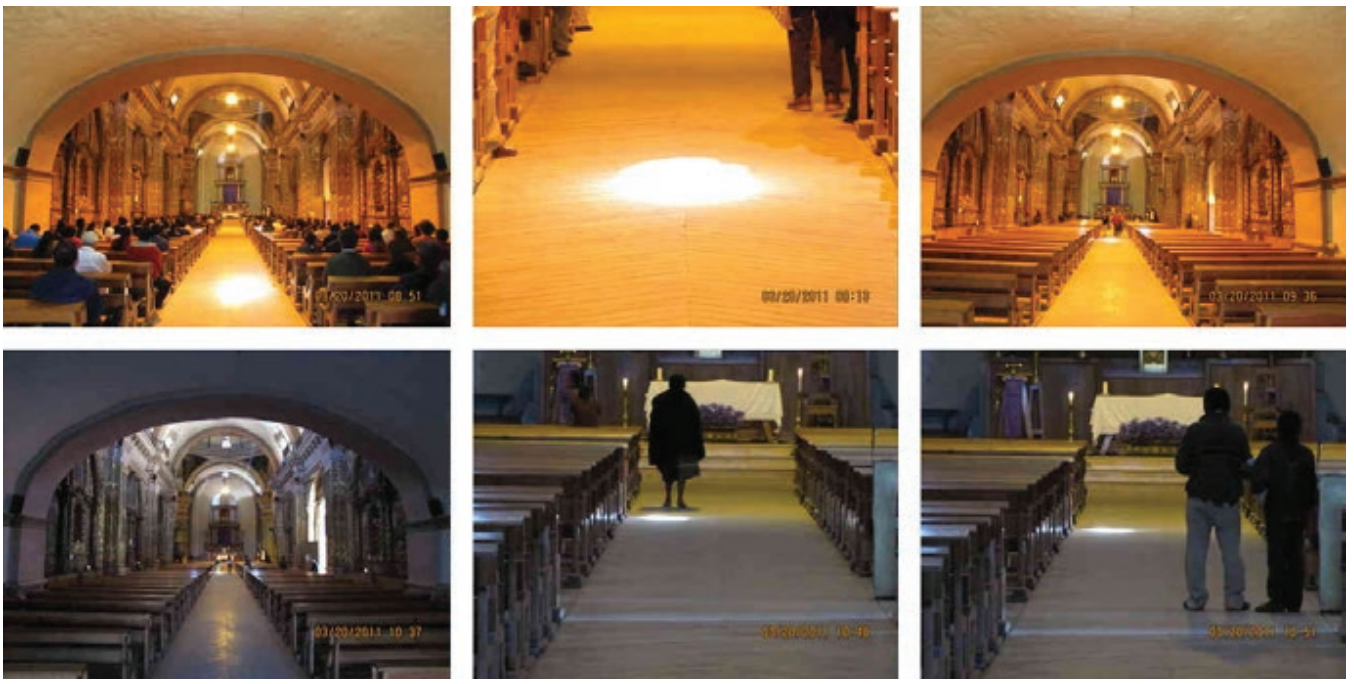

Figura 3-El movimiento de la refleja de la luz de la cúpula por el pasillo en el equinoccio en Santo Domingo.

Pero el piso original está cubierto por, al menos, uno posterior de madera, por lo que habría que investigar si la orientación original del mismo seguía la línea del Meridiano. A Markman (1984), que desconocía su significado astronómico, le intrigó el hecho de que las ventanas de la cúpula de una iglesia hubieran sido re-situadas a sólo unos centímetros de su ubicación original. Ahora podemos deducir que dichas modificaciones tenían la intención de ubicar los haces de luz en el centro del pasillo. Pudo haber imprecisiones en la obtención de la línea meridiana, o pudo ocurrir que las ventanas tuvieran que ponerse en la temporada de lluvias, cosa que es común durante la mitad del año en SCLC: estas circunstancias justificarían la necesidad de un ajuste en la construcción final. En la figura 3 se ve el mismo movimiento de la luz en el equinoccio en la iglesia de Santo Domingo.

Santa Lucía, SCLC (1643'55.55” N 92³8’11.89” O). No se sabe con seguridad cuál fue la fecha de construcción de esta iglesia (Markman, 1984). Aunque Antiguas (1991: 86) sugiere que fue construída a finales del siglo XIX, un informe del INAH señala una carta donde se especificaba que los muebles de la iglesia habían sido robados en 1819 (Anónimo 1999: 469), por lo que alguna iglesia debió haber sido construida en ese lugar, como muy tarde, a comienzos de ese siglo. Sí se sabe que fue reconstruida entre 1884 y 1892, aunque se mantuvo la cúpula original. Al igual que la de La Caridad, la cúpula de Santa Lucía se encuentra exactamente sobre el altar. El día del equinoccio, un rayo de luz viaja a lo largo del pasillo, avanza sobre la alfombra y se «arrodilla» delante de la barandilla, para luego formar un círculo en el centro del altar justo antes de desaparecer (como se muestra en la Fig. 4). En esta ocasión, el haz de luz está atenuado por el 
cristal de las ventanas de la cúpula. No se presentan en este estudio imágenes del charco de luz proyectado sobre el altar porque no disponía de un trípode lo suficientemente alto como para fotografiar la superficie del mismo. Esta iglesia es una de las construcciones más nuevas que he estudiado, en la que la luz de la cúpula traza el meridiano. Ésta y la de Guadalupe (de la que se hablará a continuación) son construcciones posteriores a la mayoría de las iglesias que tratamos aquí, e incluso a algunas misiones dadas de California (Mendoza, 2005, 2011) y Texas, (que también trataremos más adelante). No he encontrado haces de luz que tracen la línea del meridiano en iglesias construídas después del año 1825, aunque muchas de ellas todavía no han sido estudiadas.

Guadalupe, SCLC (164'17.21" N 92³7'31.98” O). Un cartel colocado en la iglesia dice que fue construida en 1835. A diferencia de las iglesias de las que he hablado anteriormente, y según la declinación corregida con la brújula Brunton el día 23 de abril de 2008, ésta no estaba orientada con exactitud de Este a Oeste, sino a $7^{\circ}$ del meridiano. Sin embargo, el techo que se veía desde Google Earth estaba tan sólo a $2^{\circ}$ del meridiano, por lo que, o el techo no se corresponde con la nave, lo cual es posible, ya que Mendoza informó de un caso similar en una misión de California (2005), o mi medida Brunton estaba equivocada. Puesto que está situada en la cima de una colina, la iglesia pudo haber sido construida a lo largo del eje longitudinal de la cresta.

Más tarde, pude comprobar que esta construcción está diseñada de manera que la luz que se proyecta desde las ventanas de la cúpula hacia el interior, traza la línea del meridiano, lo cual implica que la lectura de la brújula Brunton era incorrecta. Desafortunadamente, todos los cristales de las ventanas a excepción de uno (el más orientado hacia el sur / el más meridional) están llenos de escarcha, por lo que sólo un pequeño haz de luz se mueve a lo largo del pasillo hasta llegar al púlpito.

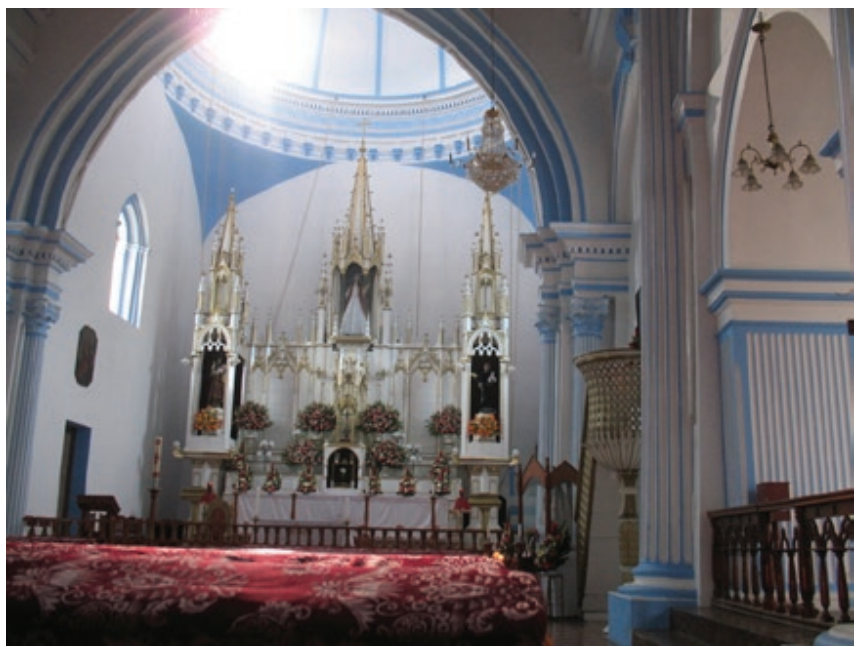

Figura 4-Reflejo de una luz del techo sobre el altar en el equinoccio, Santa Lucía. 
Una de las funciones más evidentes que podía tener un marcador equinoccial es la de anunciar que el día de Pascua era inminente. Pero, ¿eran necesarias las luces de la iglesia para avisar de la llegada de esta fecha? Con la amplia difusión de la imprenta había calendarios baratos que señalaban el día de Pascua calculado con exactitud y que se distribuyeron ampliamente en las iglesias de Europa. La primera imprenta llegó a la Ciudad de México en el siglo XVI, aunque a Chiapas no llegó ninguna hasta el siglo XVIII (Castañada 1940). En el caso de las iglesias de Chiapas construidas en los siglos XVI, XVII y comienzos del XVIII, una línea meridiana que anunciase la Pascua pudo haber sido de gran valor y los constructores pudieron haberlas diseńado así con esta intención. Sin embargo, Mendoza (2005: 90-91) señala otro uso del juego arquitectónico de la luz en las misiones del norte de la Nueva España: él sugiere que su existencia es una prueba de la creencia en el inminente apocalipsis. Su trabajo se sitúa en el contexto de las tradiciones Franciscanas pero en el caso de las iglesias de San Cristóbal de Las Casas se requieriría una investigación igualmente detallada sobre la Orden de los Dominicos, con la que todas las iglesias anteriores están relacionadas.

El equinoccio no era el único fenómeno celeste marcado en las iglesias coloniales. Mendoza encuentra que las luces del solsticio de invierno se proyectaban desde las ventanas sobre varias imágenes y elementos arquitectónicos de la franciscana Misión de San Juan Bautista (Mendoza 2005:88). Un tipo de iluminación como ésta puede encontrarse también en las iglesias de Chiapas.

En el solsticio de verano, la primera luz de la mańana arrojada a través de las aberturas de las cúpulas de Santo Domingo y de La Caridad se dirige hacia las entradas situadas en la parte sur de ambas naves. Por lo tanto, las puertas deben haber sido situadas de forma que, recibieran luz durante la construcción, dado que la colocación de las ventanas estaba determinada por la necesidad de proyectar una línea meridiana y mantener la simetría. La figura 5 muestra un rayo de luz procedente de la cúpula de Santo Domingo que ilumina la entrada de la iglesia pocos días después del solsticio. El día del solsticio de ese año, las nubes me impidieron tomar una buena imagen de la luz iluminando el centro exacto del umbral, pero hay fotos de años anteriores que documentan el fenómeno. Por otra parte, las puertas de esta entrada miden más de $4 \mathrm{~m}$ de altura y en el interior de cada una hay una puerta más pequeña de aproximadamente $2 \mathrm{~m}$ de alto. Si sólo hubieran estado abiertas las puertas pequeñas, la luz habría dibujado una figura en el centro del umbral. Es posible que el arquitecto que diseñó la colocación de las ventanas de la cúpula no visualizara el efecto de tamañas puertas abiertas, reformadas después de la primera parte del siglo XVII (Markman 1984: 175).

Como muestra la figura 6 y en contraste con Santo Domingo, la entrada sur de la iglesia de La Caridad está casi perfectamente marcada por la luz procedente de la cúpula el día del solsticio. El umbral está completamente iluminado en la mañana de este día 
y de otros dos antes y después del 21 de junio. Las puertas de la entrada más pequeña de la Caridad no detienen la luz que llega al centro del umbral. Además, la iglesia fue dedicada a Santo Tomás, cuyo día se celebra el 27 de diciembre. Si hubo fiestas fijadas para este día, tuvieron que haber sido impresionantes tardes de precesión a través de una luminosa luz en la entrada.

El mismo día del solsticio, en la Capilla del Rosario, situada al sur del altar, la luz procedente de una ventana lateral ilumina parcialmente la figura de la Virgen María. Ésta está colocada hasta el fondo del nicho pero si hubiera estado centrada, la luz habría iluminado de lleno su figura. (Figura 7).

Catedral de SCLC (1644'15.16” N 92³8'16.57” O). Esta construcción carece de cúpula. La iglesia se abre hacia el oeste por lo que, si las puertas estuvieran abiertas, la puesta del sol equinoccial la iluminaría por dentro. Curiosamente, la fachada está orientada a $7^{\circ}$ de la perpendicular a la nave (Markman, 1984: 376, fig. 103), pero esto no afecta a la entrada de los rayos del sol de poniente. Su vecina y más antigua iglesia en SCLC, San Nicolas, también carece de cúpula. Ésta está orientada hacia el sur de cara a la plaza principal ( $87^{\circ}$ por Google Earth) por lo cual, sus ventanas laterales proyectarían la luz hacia sus antímeros durante el equinoccio. Posiblemente las ventanas laterales iluminen el altar en el solsticio, pero nunca he estado allí ningún día en el que la iglesia no estuviera cerrada o el cielo nublado.

En Sta. Lucía la entrada no está orientada hacia el sur, sin embargo hay un rayo de luz del solsticio que impacta sobre la base de una pintura de la virgen recientemente acristalada. La luz del solsticio hubiera iluminado una imagen colocada, aproximadamente, a un metro del suelo. Una posible iluminación de cruce de cuartos se verá más adelante. En Guadalupe tampoco hay ninguna entrada hacia el sur que ilumine el interior de la bóveda, sólo una instalación con una base tal vez más grande de lo que necesitaría la actual imagen acristalada de santos acristalada.

El simbolismo del rayo de luz que ilumina la entrada sur de la iglesia en el solsticio de diciembre merece un estudio más extenso. Tanto el solsticio como el equinoccio eran días importantes para los católicos y para los mayas prehispánicos. Aveni y Hartun (1986), por poner un ejemplo, han estudiado la importancia de tales orientaciones para los mayas prehispánicos. Existen diagramas cósmicos de los mayas que muestran la tierra con el sol circunscribiendo el horizonte en los solsticios y el equinoccio de entre ellos (Milbrath 1999: 30). La orientación de las iglesias o los patrones de asentamiento se pueden deducir de las direcciones de los solsticios y por lo tanto, de los puntos cardinales. Las direcciones intercardinales podrían haber tenido ahí su origen. Existen también glifos mayas que describen estas direcciones intercardinales (Newsome 2001: 218). 


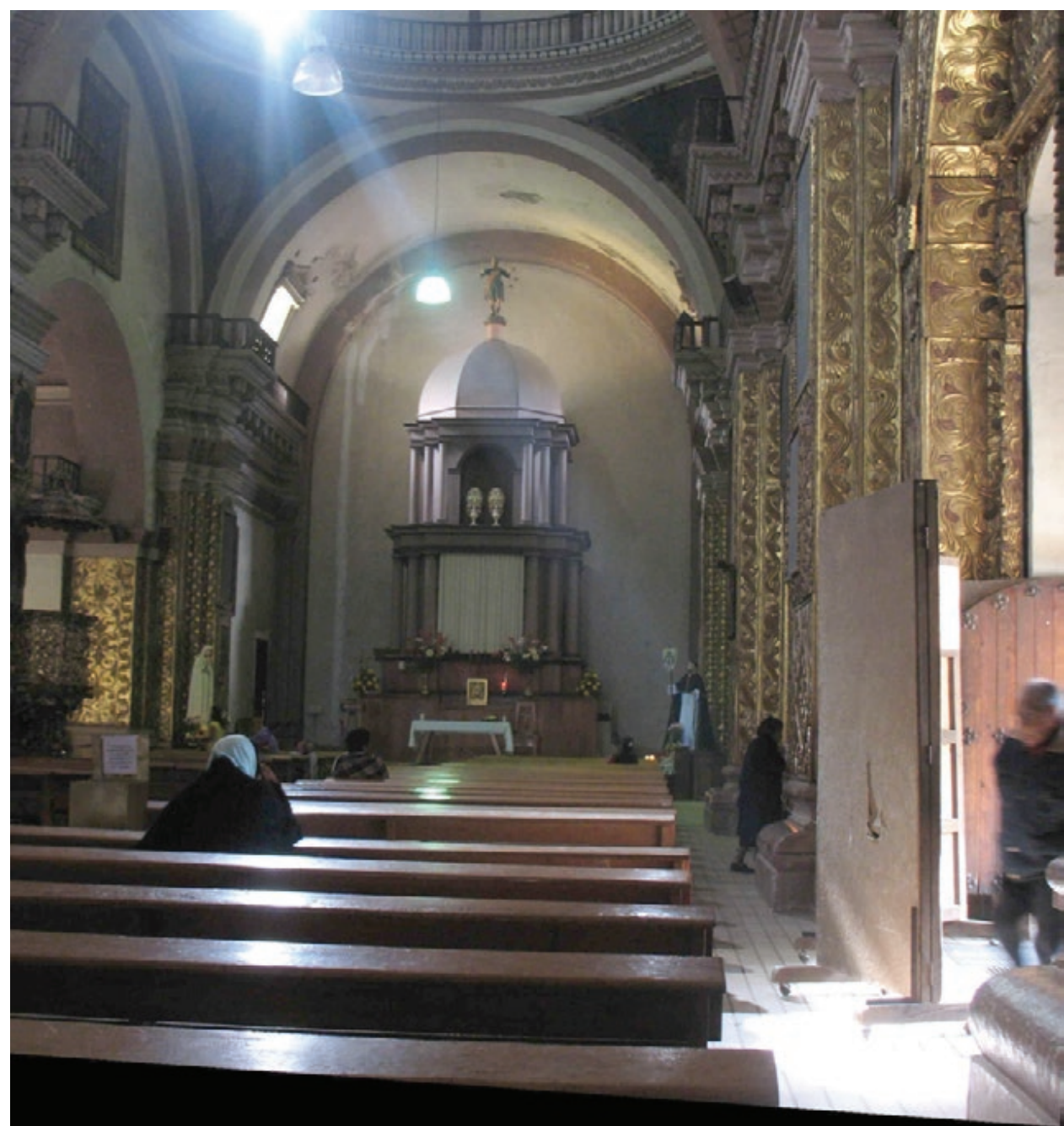

Figura 5-Solsticio refleja en la entrada sur de Santo Domingo.

La iglesia cristiana más antigua cuyos cimientos mantienen su orientación original es del siglo VI NE: Santa Sofía en Estambul. A pesar de que la cita con la que se inició este trabajo sugería que la iglesia apuntaba hacia la salida del sol en el solsticio de diciembre (SSSD), ya sea vista en mapas o a través de Google Earth, ésta se aparta sustancialmente de dicha orientación (Schibille 2009, p. 31). Sin embargo, Schibille argumenta que los cálculos originales estaban destinados a orientar la iglesia hacia la salida del sol en el día más corto del año. Análisis como éste nos permiten saber cuál era la intención inicial de la construcción. Sin embargo, tenemos ejemplos de época temprana que no 

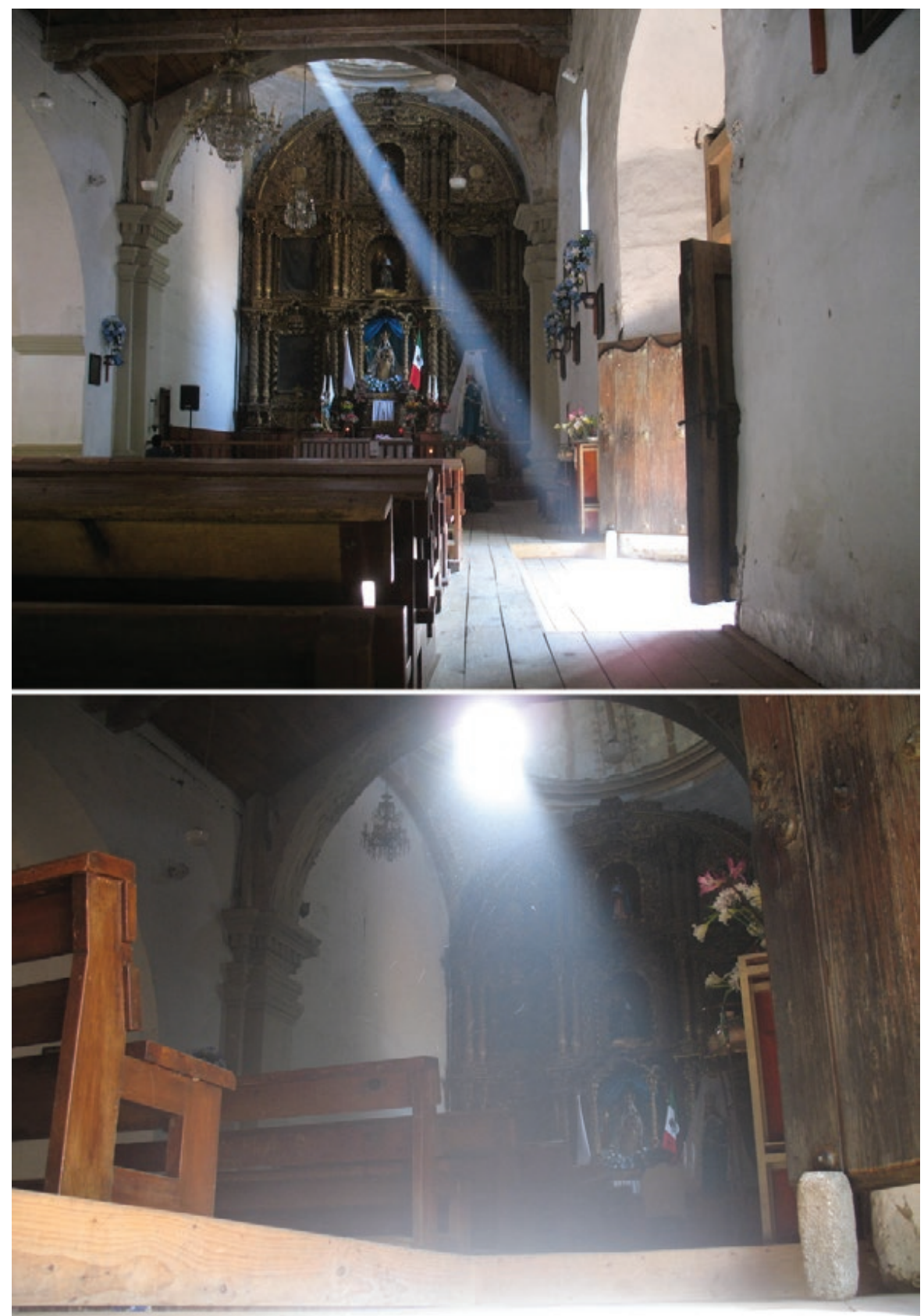

Figura 6-Solsticio refleja en la entrada sur de La Caridad. 


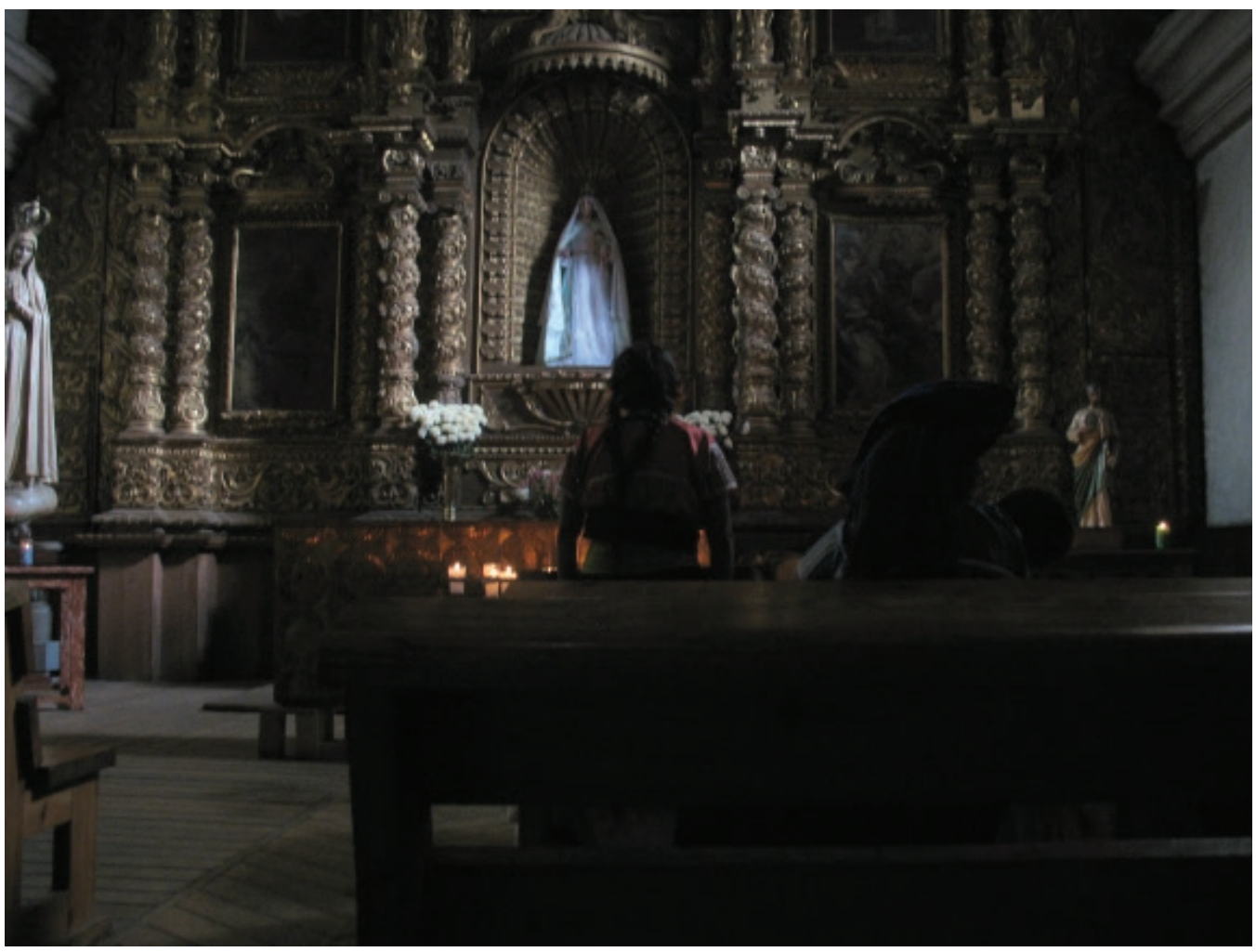

Figura 7—Ventana de luz reflexión sobre la Virgen de la Caridad.

indican que se pretendiese seguir este u otro patrón. La Iglesia de la Natividad está más orientada hacia el equinoccio, con un acimut aproximado de 98․ La iglesia de San Juan de Letrán, la primera de Roma, está a medio camino entre las dos anteriores, con una orientación de aproximadamente $78^{\circ}$ (acimut de Google Earth Pro).

En la época colonial de la Nueva España y Perú, la mayoría de las iglesias cristianas estaban orientadas al equinoccio, al menos en las zonas urbanas. Pero, como veremos más adelante, hay casos de iglesias rurales mayas que presentan notables excepciones.

Se sabe que los mayas prehispánicos llevaban la cuenta de muchos fenómenos astronómicos y que tales orientaciones son bien conocidas incluso más allá de Mesoamérica. A veces las construcciones prehispánicas fueron utilizadas como cimientos de las iglesias coloniales. Tal vez el ejemplo más famoso sea la catedral de la Ciudad de México construida sobre el Templo Mayor Azteca. Otro ejemplo es la Iglesia de Santo Tomás, en Chichicastenango, Guatemala, orientada hacia la puesta de sol del solsticio de diciembre, que se encuentra sobre un templo maya destruido que contaba con 18 escalones, 
uno por cada mes Maya tradicional, que hoy conducen al templo católico. Sin embargo, esta correlación no siempre se cumple. La entrada escalonada a la Gran Pirámide de Cholula tiene un acimut de aproximadamente $114^{\circ}$, el SSSD y la iglesia de la parte superior está orientada a 106,50 (según Google Earth Pro). Ninguna de las iglesias que se describen en este capítulo tiene una relación conocida con estructuras prehispánicas. No obstante, algunos aspectos de las creencias prehispánicas pueden haberse integrado en su arquitectura.

Es posible que algunos rayos de luz procedentes de las ventanas colocadas estratégicamente en algunas construcciones funcionaran para dar cabida a las creencias mayas dentro del ritual católico. Hay un día que puede servirnos de ejemplo para este caso: el día de cruce de cuartos fue marcado en al menos una y posiblemente dos iglesias en SCLC. Este día se encuentra entre los más importantes del calendario festivo y las peringraciones actuales de los maya tojolabales (Furbee 2011).

\section{EL DIA CRUCE DE QUARTOS, SAN CRISTOBAL DE LAS CASAS}

Actualmente los días de cruce de cuartos tienen lugar dentro de un rango variable de días. Esta inexactitud se debe a la ineficacia de nuestro calendario. En las latitudes templadas estos días tienen lugar cuando el clima empieza a cambiar por ello, tanto los celtas como los mayas les dieron mucha importancia. En la región donde vive del grupo indígena tojol'abal que viven al oeste del SCLC, como en gran parte de México indígena, estos días se ubican en los meses cuyo final marca un cambio drástico en las precipitaciones señalando las dos estaciones de lluvia y las dos de época seca (Furbee 2013).

El 4 de febrero 2009, en el inicio del período de días de cruce de cuartos, las nubes eran abundantes y los destellos de luz solar, por debajo y por encima del púlpito, fueron brevemente visibles en la iglesia de Santo Domingo en SCLC. El 7 de febrero sí estaba despejado y un haz de luz azul brillante cayó sobre el púlpito (Fig. 8). La imagen de la izquierda de la figura 8 fue tomada el 8 de febrero y la imagen de la derecha fue tomada al día siguiente, cuando el sol parecía abandonar su tarea. La luz del sol sobre el púlpito hizo que el pan de oro, que por lo general parece negro, se tornara en oro brillante (Fig. 8). Al ver esta luz en Santo Domingo, me apresuré a la cercana iglesia de La Caridad, en la que, en ese día, un rayo de luz golpeaba allí donde debería haber estado el púlpito en el lado norte, donde hay una cámara lateral, pero La Caridad carece de y si alguna vez hubo uno, fue eliminado púlpito -como apunta el vigilante-. Queda un ojo de hierro en la pared del lado norte, que podría haber servido para sostenerlo - no hay ningún elemento semejante en el lado sur-. Por lo tanto hay siquiera una pequeńa posibilidad de que la Caridad también tuviera la misma marca de luz de los días de cruce de cuartos que la iglesia de Santo Domingo. Pero sería necesaria una investigación de archivo para resolver esta cuestión. 

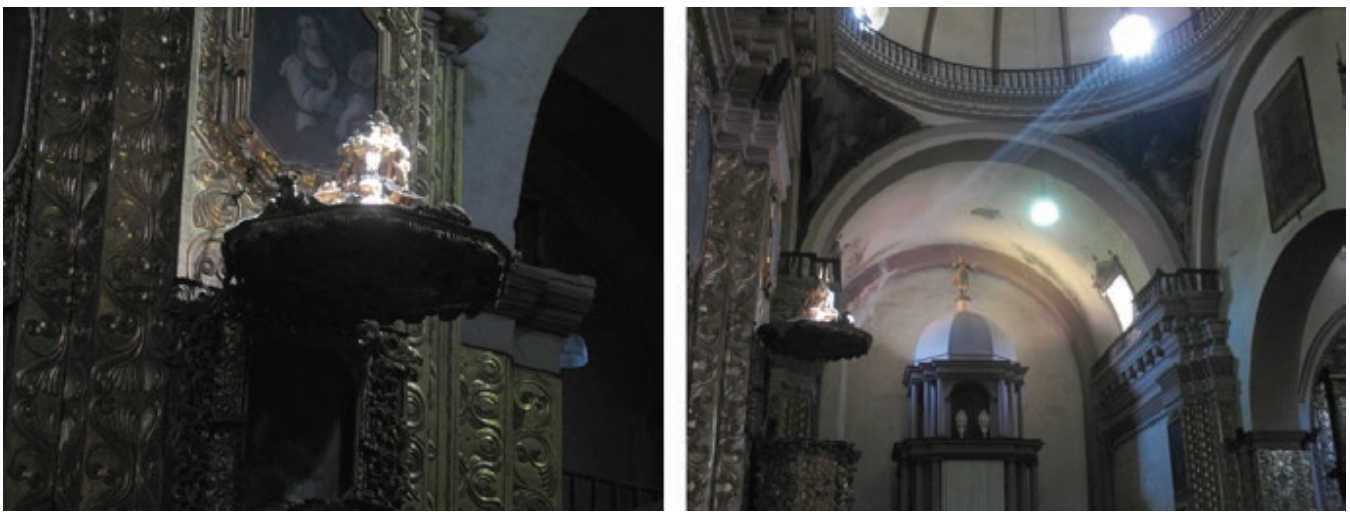

Figura 8-Cruz quarto día de iluminación de día de púlpito en Santo Domingo.

El púlpito de la iglesia de Santa Lucía se encuentra situado al sur, justo en el lado opuesto (Fig. 4) en el que un rayo de luz impacta el día 6 de febrero (Fig. 9). No existe ninguna evidencia arquitectónica de que hubiera algún púlpito en la pared norte. Es de suponer que el de la parte sur se ilumina otro día de cruce de cuartos, alrededor del 6 de agosto, pero no pude estar allí para observar este fenómeno.

En la cúpula de La Caridad otro rayo de luz marca el día del equinoccio, esta vez en la tarde. El día 4 de febrero, un haz de luz ilumina la figura de San Juan, situada en la parte superior del retablo; posteriormente, el 13 de marzo, el rayo de luz pasa a iluminar a San Antonio de Padua -situado debajo de San Juan-, y finalmente llega hasta la Virgen de la Caridad el día del equinoccio (Fig. 10). La iluminación de los Santos podría interpretarse como el anuncio de las celebraciones previas a la Semana Santa. Es interesante apuntar, como dato adicional, que la imagen de San Antonio se encuentra en un nicho cuyo marco se iluminó de un dorado brillante, mientras que las partes superior e inferior del nicho se mantuvieron en penumbra. Esto pude verlo el 18 de junio de 2011, dos días antes del solsticio y cinco días después de la fiesta del santo pero no he podido determinar cuál era el origen de esta luz que se desvaneció con las nubes que pasaron.

Quinta de San Martin, SCLC (16²5’25.59” N 9240’18.87” O). No tengo noticia de la antigüedad de esta pequeña capilla. Su orientación con declinación corregida es $126,5^{\circ}$, obtenida con una Brunton colocada sobre un trípode, a 9,5 del día de cruce de cuartos (el acimut de Google Earth Pro fue de $128^{\circ}$, algo más cercano). La luz del solsticio de verano requeriría una ventana trasera con un ángulo de $25^{\circ}$ para brillar dentro de la iglesia con un acimut de $126,5^{\circ}$. Sin embargo, no hay evidencias de ninguna ventana en la parte trasera de esta iglesia. 


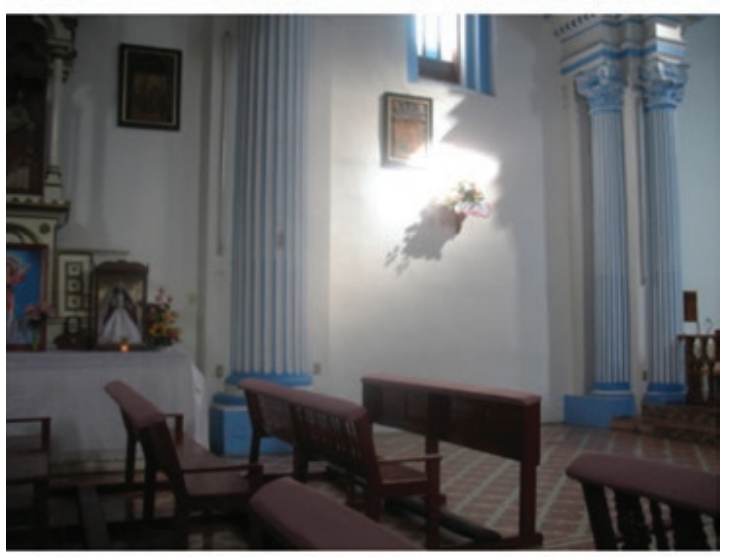

Figura 9-La reflexión de la luz en febrero 6, Santa Lucía
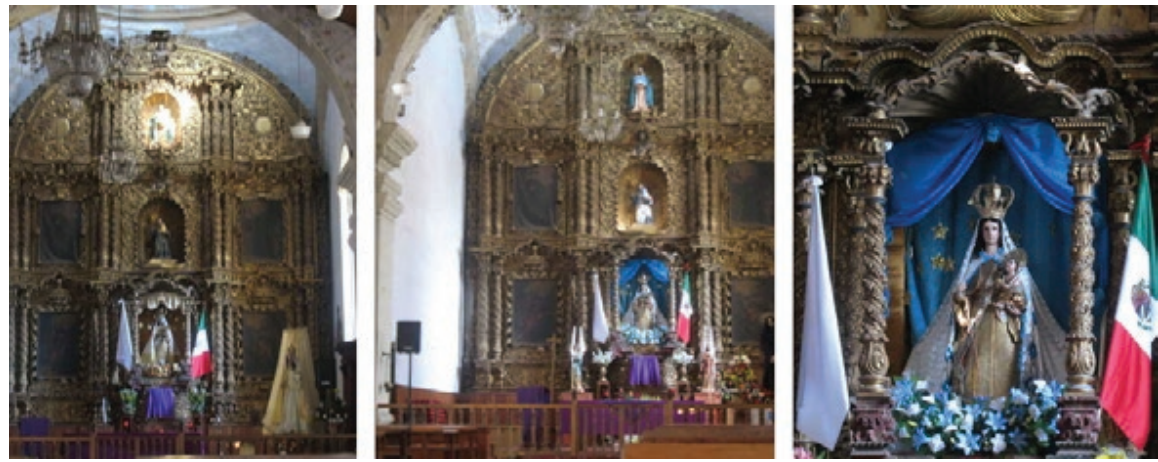

Figura 10-Reflejos de luz desde las cúpulas ventanas de la Caridad santos.

\section{IGLESIAS DE FUERA DE CHIAPAS}

San Felipe Ecatepec ( $16^{\circ} 43^{\prime} 26.22^{\prime \prime}$ N 9240'19.68” O). Esta iglesia se encuentra en la periferia norte de la moderna SCLC. No estaba abierta cuando la visité. Mis medidas Brunton tomadas durante una tormenta verifican las de Google Earth: la iglesia se abre hacia el oeste a $279^{\circ}\left(280^{\circ}\right.$ por Google Earth $)$ aproximadamente $9^{\circ}$ mas que el equinoccio. La iglesia es paralela a la carretera en su parte norte.

La Quinta del Asserado (coordenadas no disponibles). Justo al noreste a pocos kilómetros de SCLC se encuentra la hermosa la Quinta del Asserado. Esta pequeña iglesia está orientada a aproximadamente $327^{\circ}$ (según mi brújula Brunton). Si esto es correcto, corrigiendo del mapa de Markman (1984: Fig. 134) hacia el norte, la pequeña ventana del lado Este se abre con un acimut de $97^{\circ}$ aproximadamente. Si la colina del Este tiene una altura de unos $23^{\circ} 30^{\prime}$, que no medí, pero que podría ser su altitud 
aproximada, el 21 de marzo de 1600, a las 8:56 AM, el sol se hubiera elevado a 9704' y podría haber iluminado el altar desde la ventana lateral. Obviamente, estas medidas requerirían una revisión.

Templo de San Juan, Chamula (1647'17.72” N 9241'21.76” O). Una famosa iglesia indígena, San Juan de Chamula, situada justo al noroeste de SCLC, puede haber sustituido una ruina anterior $\left(16^{\circ} 46^{\prime} 58.20^{\prime \prime} \mathrm{N} 92^{\circ} 41^{\prime} 31.87^{\prime \prime} \mathrm{O}\right)$. La fecha de construcción de esta iglesia situada en la colina que hay sobre la ciudad aún no se ha determinado, pero puede ser del siglo XVI. Pronto descubrí que no estaba permitido entrar en la esta iglesia de hoy ni con una cámara, ni con una brújula, y Markman no presenta ningún plano, pero afortunadamente la iglesia es muy visible en Google Earth. San Juan Chamula tiene un acimut de 226 según Google Earth Pro, que es casi exactamente la dirección de los puntos intercardinales. La iglesia está dedicada a San Juan Bautista, que es enormemente celebrado allí el día 24 de junio (Gossen 1999: 272). Desde el 21 de junio la puesta de sol debería estar a $294^{\circ}$, por lo que deducimos que la orientación de la iglesia no tiene relación con el día de su festividad. Sobre la puerta de entrada de la fachada de iglesia, hay una puerta que se abre a un balcón. Si el ángulo desde la puerta hasta el altar fuera de aproximadamente $12^{\circ}$, la puesta de sol del 21 de junio del año $1700 \mathrm{NE}$ habría sido de unos $291,5^{\circ}$, por lo que no habría habido ningún rayo de luz que llegase al altar desde la entrada. La otra iglesia abandonada y en ruinas, San Sebastián, que se encuentra sobre una colina del municipio y está orientada a $217^{\circ}$ según Google Earth Pro, pero este acimut no se corresponde con ninguna orientación de interés astronómico.

San Lorenzo, Zinacantán (1645’36.09” N 9243’24.26” O). Cerca de San Juan Chamula, se encuentra esta iglesia de principios del siglo XVI. Según mi brújula Brunton, la construcción tiene un acimut de $299^{\circ}$, mientras que Google Earth sugiere 300º, que son $4^{\circ}$ o $5^{\circ}$ grados menos que los de la puesta de sol del solsticio de junio del 1700 $\mathrm{AD}$, que sería de $24^{\circ} 26^{\prime}$. Existe otra pequeña iglesia con el nombre de San Sebastián que se encuentra en el pueblo de Zinacantán, a unas pocas cuadras al noreste de San Lorenzo. Hay una fecha sobre la entrada que indica que el año de construcción fue el 1832, aunque estas fechas no siempre son exactas. La iglesia no estaba abierta cuando fui, pero la línea que trazan sus contrafuertes exteriores tiene una orientación aproximada de $100^{\circ}$. Está ubicada a lo largo un valle, lo cual puede ser la causa de su orientación. Hay un número significativo de iglesias que no han sido estudiadas sistemáticamente y que tienen un acimut de alrededor de $100^{\circ}$, pero no tengo ninguna hipótesis acerca de las razones de este patrón.

San José, Comitán Domínguez ( $16^{\circ} 15^{\prime} 11.72^{\prime \prime}$ N 92 $7^{\circ} 58.58^{\prime \prime}$ O”). La iglesia no es de la época colonial sino que data de 1910 . Cuenta con seis ventanas en la cúpula en lugar de las cuatro que eran características de la época colonial. Cuenta con un acimut de alrededor de $325^{\circ}$ según Google Earth, una desviación sustancial de Este a Oeste, pero 
sólo a $10^{\circ}$ de $315^{\circ}$, la dirección de los puntos intercardinales. Dada su tardía construcción, es de suponer que su orientación acorde a los puntos cardinales es consecuencia de la necesidad de encajar en las alineación de las calles. Según la investigación realizada por María Cruz La Chica (comunicación personal) el día antes del solsticio de junio de 2011 había un rayo de luz en la tarde que se proyectaba sobre la capilla, pero éste no cayó sobre ningún punto de interés que no fuera la pared del fondo norte del altar.

Zapaluta, La con la brújula Brunton sobre trípode con la brújula Brunton $\underline{\left(16^{\circ}\right.}$ 7’8.15” N 92²'58.98” O). La iglesia indígena de La Trinitaria, (La Santísima Trinidad de Zapaluta), no puede compararse con una iglesia ladina, ya que la ciudad fue y es predominantemente indígena. La iglesia se abre a un acimut de $246^{\circ}$ con la brújula Brunton sobre trípode, casí al igual que las calles que hay a ambos lados de la misma (Google Earth y Brunton). Su antigüedad no se conoce, pero la primera noticia que tenemos de ella data de 1819 (Markman 1984: 254-255). La puesta de sol del solsticio de diciembre en el año 1700 habría sido vista a $245^{\circ} 45^{\prime}$. Al igual que varias poblaciones e iglesias de Chiapas, la iglesia de Tzimol y las dos de Teopisca -como el pueblo en sí- están orientadas en general hacia los solsticios. La iglesia de Santo Tomás en Chichicastenango, Guatemala, y la iglesia de Casma, en Perú, son otros ejemplos de los principales asentamientos urbanos en los que las construcciones coloniales están orientadas al solsticio.

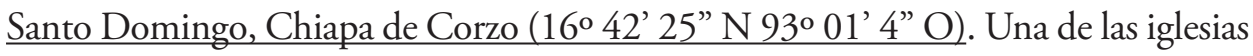
más antiguas de Chiapas es Santo Domingo, construida entre 1576 y 1588 . Hoy en día está situada en el entorno urbano pero no era así cuando se construyó. El acimut tomado con la Brunton en el suelo del centro del pasillo, desde la parte trasera de la iglesia hasta el altar, es de $125^{\circ} 44^{\prime}$-con declinación corregida-. El techo de la iglesia tiene casi el mismo acimut: $126^{\circ}$ o $127^{\circ}$ aproximadamente, según Google Earth Pro, por tanto, la iglesia no está orientada hacia el solsticio de deciembre (114020' en el año 1576). La cercana orilla del río hoy día tiene un acimut de unos 129030', por lo que la iglesia pudo haber sido alineada según la dirección del río. Sin embargo, es posible que la orientación estuviera en función del amanecer del solsticio, de $114{ }^{\circ} 30^{\prime}$ con declinación extrema de $12^{\circ}$ en ese momento y sin medios con los que corregir la orientación de la construcción. Tanto recientemente como en 1947, la declinación fue de más de $8^{\circ}$ en este lugar.

No hay ventanas en la cúpula principal, pero hay una ventana circular situada sobre el altar mayor, parecida a la de San Pedro, en Lima, de la que hablaré más adelante, y hay otra ventana, también circular, en la entrada principal mirando hacia el altar. La que está sobre éste tiene un vidrio de color amarillo, pero la luz del amanecer del solsticio debe poder penetrar en la iglesia a través de él. Si el sol se hubiera elevado $12^{\circ}$ antes de atravesar la ventana, el acimut de la salida del sol del solsticio de invierno de 1700 DC habría sido de $119^{\circ} 22^{\prime}$ a $12^{\circ} 12^{\prime}$ a las 8:40 AM. Todavía no he podido observar en Santo Domingo el amanecer del solsticio de diciembre. 
En cualquier caso, los constructores tuvieron en cuenta algunos fenómenos astronómicos a la hora de construir la iglesia de Santo Domingo en Chiapa de Corzo. En el solsticio, el día 21 de junio de 2010, pude observar cómo un rayo de luz caía sobre la cabeza de una estatua que representaba a Dios Padre con su cetro, en un retablo situado en el centro de una cámara lateral (Fig. 11).

Hay iglesia colonial en Chiapa de Corzo que no puede clasificarse fácilmente en la oposición indio / ladino. Data, como muy pronto, de 1681 (Markman 1984: 118), pero esta fecha no es del todo segura. De esta iglesia, llamada también San Sebastián (1642'14.46” N 93ㅇ'42.20" O), ahora tan sólo quedan unas ruinas en una colina que domina la ciudad. Según la orientación de Google Earth Pro, $305^{\circ}$, la construcción sigue la cresta de la colina, a $10^{\circ}$ de la dirección de los puntos intercardinales.

Teopisca. En la pequeña localidad de Teopisca nos encontramos con dos iglesias, una es la de San Agustín (16²’31.18” N 92²8’17.88” O), que data de antes de 1626, aunque la construcción actual puede ser de 1714 (del Anaya Avila y el., 2010: 50); y

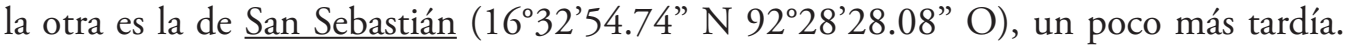
Ambas carecen de cúpula y abren sus puertas hacia la puesta de sol del solsticio de diciembre (PSSD) con orientaciones de 247030' y 251 $1^{\circ}$ en sus respetivos techos según puede verse con Google Earth. En ambos casos, situando la brújula Brunton en el suelo del centro del pasillo, la alineación desde el altar hacia la entrada era de $241^{\circ}$. Markman

Figura 11-Luz incidiendo sobre una estatua de Dios Padre, en la iglesia de Santo Domingo en Chiapa de Corzo.

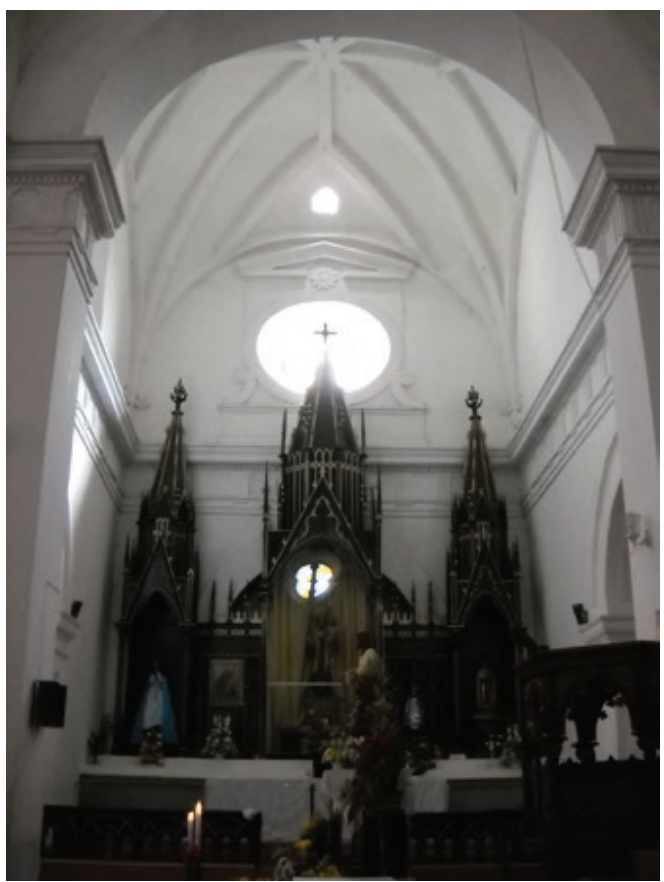


(1984: Ch 23) describe una «Iglesia de Teopisca», refieriéndose a San Agustín, pero no menciona la iglesia que se encuentra en el extremo norte de la ciudad, San Sebastián. San Agustín está situada en un ángulo marcadamente distinto al de las calles de la ciudad (Fig. 12) que están orientadas a $254^{\circ}$. Puesto que ambas están orientadas hacia las colinas con una elevación de $10^{\circ}$, la puesta del sol real pudo no haber sido de $245^{\circ} 11^{\prime}\left(-0,5^{\circ}\right.$ de refracción en un horizonte con nivel), sino de $242^{\circ} 24^{\prime}$. Esto se acerca al acimut leído con la Brunton de $241^{\circ}$. Ambas iglesias techas estarían alineadas con la puesta de sol del solsticio de diciembre (PSSD) si estuvieran en un horizonte llano. Quizás la alineación de la iglesia no fue precisa por falta de corrección de la declinación. El trazado de las calles debe seguir algún otro principio. Curiosamente, con Google Earth se puede observar que muchos campos de los Mayas alrededores de Teopisca también coinciden con el acimut general de $245^{\circ}$. A través de Google Earth pueden encontrarse otros campos situados en el área Maya con una alineación astronómica significativa que aún no se ha investigado de forma sistemática.

Aunque entre estas dos iglesias una es ladina (San Agustín) y otra indígena (San Sebastián), ambas tienen idéntica orientación astronómica. Recordemos que en SCLC, las dos iglesias más antiguas comparten estas características astronómicas: la iglesia indígena de La Caridad y la iglesia ladina de Santo Domingo. Los arquitectos diseñaron idéntico juego de luces para las dos congregaciones de fieles: la iglesia ladina de Santo Domingo en SCLC fue construida para marcar el día de cruce de cuartos -tan importante para los indígenas-, mientras que, a menos que hubiera un púlpito, la iglesia indígena de la Caridad no lo marcaría.

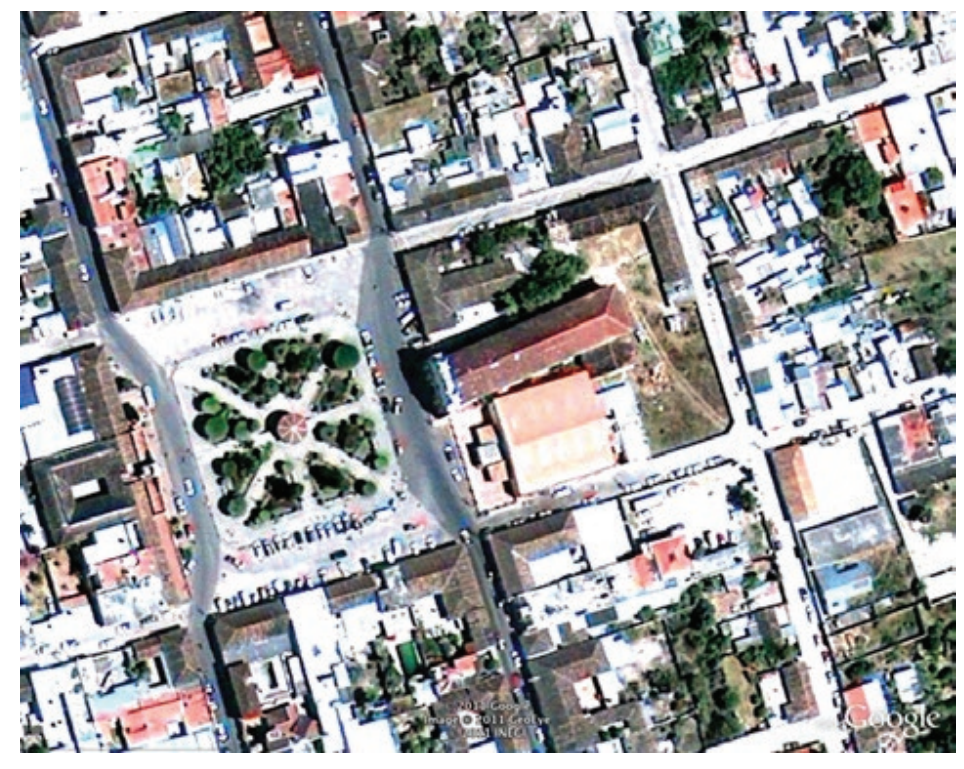

Figura 12- Iglesía Agustín, Chiapas, calles $254^{\circ}$. 
Coneta (1553’41.07” N, 9156’24.69” O). Se trata de una misión abandonada en el suroeste de Comitán. El mapa de Markman (1984, fig. 188) no se corresponde con los acimuts actuales de la misión. La nave de la iglesia está orientada a 238 $01^{\prime}$ según la declinación corregida con la Brunton (utilizando los puntos medidos centrales y el trípode) y a $238^{\circ}$ según Google Earth Pro. Estas lecturas están a $13^{\circ}$ de la dirección de los puntos intercardinales (que están a 225). Una imagen de Google Earth Pro del 23 de diciembre de 2005 muestra los restos de los muros que rodean el recinto en la mitad delantera de la iglesia. El acimut de la pared orientada hacia el sur es de $234^{\circ}$, por lo que está más cerca de la dirección intercardinal.

El convento no está colocado en ángulo recto con la iglesia de Coneta. Teniendo en cuenta los acimuts de Google Earth, un espectador que mire desde la pared trasera a través de los departamentos hacia una hipotécica ventana en la pared del fondo del convento se situaría a $326^{\circ}$, es decir, a $11^{\circ}$ de la dirección intercardinal de $315^{\circ}$. La vegetación impide tomar las medidas con la Brunton. Otra misión de la zona, Coapa, tiene calles orientadas en esta dirección general (Lee 1977, véase más adelante). Curiosamente, al igual que la misión de San José, en San Antonio, Texas, los muros que rodean la de Coneta no se corresponden exactamente con el acimut de la iglesia. Ambos casos sugieren una falta de precisión en la colocación de la misión o, si la iglesia actual se construyó más tarde que los muros, la declinación podría haber variado en esos años y los clérigos se limitaron a seguir su brújula. Sobre el terreno, es difícil apreciar que la orientación de las paredes difiere de la de la iglesia pero una simple triangulación podría haberlas hecho coincidir.

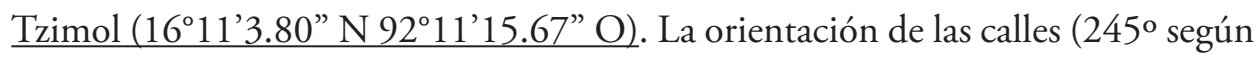
Google Earth), se dirige hacia la puesta de sol del solsticio de diciembre PSSD, pero, curiosamente, la iglesia está desviada $\left(257^{\circ}\right)$ en relación a las calles que la flanquean. Otras ciudades coloniales están orientadas hacia el solsticio. Por ejemplo, las calles de la ciudad de Casma en la costa de Perú están orientadas a 24525’. La PSSD en el año 1500 NE habría sido de 246³6'. El pueblo de Chichicastenango, en Guatemala y su iglesia principal, Santo Tomas, que pueden verse desde Google Earth, tienen la misma orientación, aunque la iglesia se abre hacia la puesta del sol del solsticio de junio, no hacia el amanecer. Sin embargo, la mayoría de las ciudades coloniales no presentan ese acimut. Por poner un ejemplo, la parte más antigua de la ciudad colonial de Arequipa, Perú, está orientada a $114^{\circ}$, es decir, hacia la salida del sol del solsticio de diciembre, a pesar de que el antiguo convento del siglo XVI está orientado al equinoccio. El sitio arqueológico de Chiapas, México, Tenam Puente, cerca de la moderna ciudad de Tzimol tiene una orientación de alrededor de $232^{\circ}$, a $7^{\circ}$ del día de cruce quartos, $225^{\circ}$. Por lo tanto, el patrón de PSSD de Tzimol no se remonta a los mayas prehispánicos más antiguos. Sin embargo, las paredes de la misión de la cercana Coneta estaban orientadas de forma similar, a $234^{\circ}$. En cualquier caso, sería necesaria una investigación mucho más profunda para entender estos patrones. 
Coapa («lugar de las serpientes»; sus coordenadas no están disponibles, aunque está cerca de la ciudad de Coapa, en el Camino Real de Coneta a Comitán). Se trata de otra misión abandonada, que se inició hacia el final del siglo XVII. Como hemos visto, los acimuts de Markman no son muy confiables pero, en este caso, el mapa (1984, Fig. 170) puede ser comparado con otra versión publicada (Lee 1977, Fig. 12.2). Por tanto, podemos confiar en la imagen corregida de la figura 13, que muestra una iglesia con un acimut de $247^{\circ}$. Este acimut se logró mediante una corrección de la declinación de $6^{\circ}$ necesarios para 1976, año en el que se llevó a cabo la excavación. El programa de software Starry Night apunta que el 21 de diciembre de 1630 NE, el sol se habría levantado a $249^{\circ} 9^{\prime}$, con $-0,5^{\circ}$ de elevación. La diferencia de $2^{\circ}$ sugiere o bien la falta de tablas de declinación, o falta de precisión en la construcción. La declinación podría ser incorrecta si la fecha en la que se diseñó el mapa también lo fuera. Mi intento de hallar la respuesta mediante Google Earth, para volver a medir el acimut del suelo, no tuvo éxito por la abundancia de vegetación. El trazado de la comunidad de Coapa que rodeaba la iglesia, que ahora es apenas visible sobre el terreno, se organizó en función de las direcciones intercardinales (Lee 1977) pero, en todo caso, la alineación de la iglesia no se corresponde con la de las calles. Hay tres estructuras unidas a la misión. La figura [17] de Markman muestra que sólo la iglesia está orientada a la puesta del sol del solsticio de diciembre, lo que sugiere que esta orientación no era característica de todos los edificios del complejo de la misión, pero sí de las iglesias. El acimut de las otras construcciones $\left(214^{\circ}, 228\right.$ y $235^{\circ}$, Fig. 13.) se aproxima a la orientación de los puntos intercardinales $\left(225^{\circ}\right)$.

San Nicolás Aquespala (1549’3.68" N 91 $\left.{ }^{\circ} 56^{\prime} 10.30^{\prime \prime} \mathrm{O}\right)$. Aquespala fue fundada a mediados del siglo XVI. Está ubicada al sur de Coapa, cerca de la frontera con Guatemala en el Camino Real, al igual que Coneta y Coapa. La figura 177 de Markman (1984) muestra la fachada orientada a unos $194^{\circ}$, más de $6^{\circ}$ de declinación, suman $200^{\circ}$ aunque Google Earth Pro sugiere 206 ${ }^{\circ}$. En cualquier caso no corresponde con los acimuts de las otras iglesias estudiadas. Sin embargo, la línea que conecta el centro de la

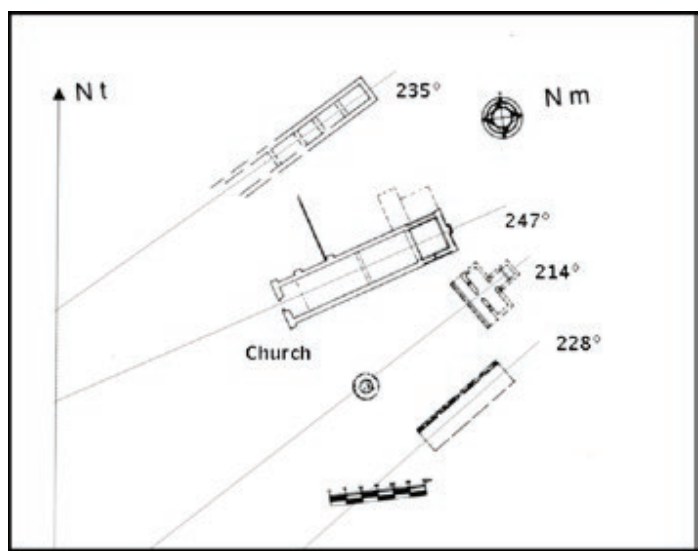


nave con otro edificio importante orientado hacia el Este según Google Earth y visible sobre el terreno, da un acimut de $112^{\circ} 43^{\prime}$ que es, aproximadamente, el amanecer del solsticio de diciembre. No conozco otros casos de acimuts relacionados con el calendario solar que se sitúen entre dos estructuras de iglesias coloniales. Es posible que debido a su fecha temprana, las preocupaciones indígenas fueran consideradas de mayor importancia por lo que se levantaron dos estructuras para marcar el solsticio. La segunda estructura podría ser un convento, pero es cuadrada en su base, no tiene la típica forma rectangular.

Ixtapa (1648'10.96” N 9254'15.40” O). Al este de SCLC se encuentra Ixtapa, una antigua ciudad que data como muy tarde de 1524. Según Markman esta iglesia es una de las primeras que tiene como base una construcción muy simple (1984: 207). Desde Google Earth, la línea del techo tiene una orientación de $299^{\circ}$. Nos recuerda que la ancha iglesia de San Juan Chamula que tiene una orientación de $300^{\circ}$. Curiosamente, las calles a ambos lados de la iglesia de Ixtapa son de $293^{\circ}$, un acimut extremadamente cercano al de la PSSJ de $24^{\circ} 21^{\prime}$. Cabe preguntarse por qué la iglesia fue construida en un acimut diferente al de las calles que la rodean.

Aunque hay otras iglesias coloniales en Chiapas que parecen estar orientadas hacia el solsticio, las mencionadas anteriormente son las únicas que he estudiado sobre el terreno. Ahora entraré con más detalle en las direcciones intercardinales.

\section{DIRECCIONES INTERCARDINALES}

Como se mencionó anteriormente, Coapa es una ciudad colonial que fue planificada con base en las direcciones intercardinales (Lee 1977). Tres edificios vinculados a la iglesia, aunque no la iglesia en sí, se aproximan a las direcciones intercardinales. Anteriormente se mencionaron otros ejemplos de la orientación de los puntos intercardinales.

Las direcciones intercardinales, tan importantes para los mayas no pudieron ser marcadas por los rayos de luz solar de las iglesias orientadas a $45^{\circ}$ y $135^{\circ}$, desde las que ni el sol ni la luna pueden ser observados. Sin embargo, la orientación de la nave podría haber sido utilizada para ese fin, y tal vez calculada a partir de los puntos cardinales. Esas direcciones son calculables a partir de las del solsticio. La orientación de las calles y plazas, iglesias o edificios relacionados con ellas, podrían haber servido para marcar las direcciones intercardinales. Además de las ciudades mencionadas anteriormente, hay otras que también se trazan en función de las direcciones intercardinales. Entre ellas se encuentran: San Juan de Arco, 40,5 (Google Earth), Las Margaritas, 48²4' (Google Earth) y San Joaquín, $45^{\circ}$ (Brunton). Esta última data de 1914, pero aunque no pertencezca a la época colonial, la incluyo como ejemplo de estas orientaciones típicas de los Maya prehispánicos, que persistieron hasta hace poco. 
Un mapa temprano de la construcción de la catedral de la Ciudad de México obtenido por Tomada de S. García (publicado en Cuesta Hernández 2009: 39) muestra una iglesia pensada para ser construída de cara al Sur (Caistor 200: 49). Sin embargo, según Google Earth está orientada $5.1^{\circ}$ al Oste del Sur. El mapa muestra el centro de una iglesia determinado por el cruce de las líneas intercardinales y alineado por la luz de las ventanas de la cúpula que cruzan el altar en el solsticio de junio (amanecer y atardecer) aunque no en el de diciembre. Estas líneas no hubieran estado alineadas para que la luz entrara en estos días a menos que las ventanas estuvieran a nivel del suelo. A pesar de que no se trata del plano de la iglesia construída finalmente, éste habla mucho sobre la cosmología de los antiguos arquitectos. La larga historia de esta construcción y las negociaciones con los albañiles aztecas deberá constituir el objeto de estudios futuros.

Hay miles de iglesias coloniales en México y América Central. La investigación anterior sugiere que es necesario el estudio de otras muchas iglesias para comprender mejor la magnitud de este fenómeno. A continuación, expondremos los resultados de algunas incursiones en Texas, Lima (Perú), Islas Filipinas y Puerto Rico que suponen un comienzo en dicha investigación.

\section{IGLESIAS COLONIALES FUERA DE MÉXICO}

Aquí hablaré brevemente sobre dos misiones de Texas que datan de la última parte del siglo XVIII.

Misión de la Concepción en San Antonio, Texas (29²3’27.82” N 98²9’27.92” O). Rubén Mendoza también está investigando esta iglesia, inaugurada en 1775. Es la única de las misiones de San Antonio que ha conservado su forma original. El acimut de la Concepción, según la medida de Google Earth está a unos $274^{\circ}$, a $4^{\circ}$ de la orientación Este a Oeste. La medida que yo obtuve del convento con la brújula Brunton sobre trípode fue muy diferente de $294^{\circ}$. El 20 de diciembre del 2010 a las 10:50 am una luz brillante y rectangular se proyectó en la parte superior derecha de la puerta del pasaje del convento. Hubiera sido muy bueno haber estado allí un poco antes para verla centrada sobre la puerta.

La tarde del 21 de diciembre del 2002, George Dawson (2004) vio una pequeña mancha de luz que se desplazaba unos metros a lo largo del muro lateral y luego desaparecía de la vista, con lo que no señalaba ningún punto de interés. En cualquier caso, a las 10:00 am, a juzgar por el movimiento de la luz del amanecer del solsticio de diciembre procedente de una ventana de la cúpula, el rayo debió golpear una ventana en el centro del coro más tarde en esa misma mańana.

Los pisos de cemento, situados al noroeste de la misión y visibles desde Google Earth, tienen la orientación del amanecer del solsticio de junio. Steve Thomka, el 
arqueólogo que ha trabajado en la misión, considera modernas estas construcciones y no hay ningún otro conjunto con esta alineación. Pero, de nuevo, debería ampliarse la investigación.

Situada lejos de cualquier ciudad, es un tanto sorprendente ver que esta misión fuera construida para abrir sus puertas hacia el Oeste, como es típico de las misiones urbanas del sur. La construcción de bóvedas con cúpulas también representa una sofisticación inusual para una frontera tan lejana de la Nueva España. Por otra parte, era una misión importante que marcó la reivindicación del norte de la Nueva Espańa en lo que hoy es Texas.

Misión de San José en San Antonio, Texas. La Misión de San José y San Miguel de Aguayo (2921'44.49” N 98²8'45.89” O) se fundó en 1720. La cúpula de San José se derrumbó en el siglo XIX, pero existe una imagen que muestra que gran parte de la estructura sobrevivió, incluyendo una parte importante de la cúpula (Fisher 1998, p. 49 y 69). Ha habido excavaciones recientes en este lugar (Thomka et al. 1999). Al igual que Coneta, Chiapas, la nave de la iglesia de la misión no tiene el mismo acimut que las paredes circundantes. Según Google Earth, las paredes están orientadas a $296^{\circ} 45^{\circ}$, la iglesia a $296^{\circ} 48^{\circ}$, y el convento, situado en la parte trasera en un ángulo de $302^{\circ} 00^{\prime}$ Dawson (2004) apunta que el acimut de la misión es de $294^{\circ}$, medido con brújula. La iglesia se abre aproximadamente a la puesta del sol del solsticio de junio.

El 21 de junio de $1720 \mathrm{NE}$ a las 20:21, el sol se habría puesto a 29704', a -0.50” sobre la llanura. El acimut de la iglesia de 294054' correspondería con el atardecer del 21 de junio de $1720 \mathrm{NE}$ de $24^{\circ}{ }^{\circ} 1^{\prime}$ ' con el horizonte a 3051', posiblemente la altura del muro de la misión. Las paredes de estos muros, a 294054', están muy cerca de la puesta de sol sobre el horizonte llano del solsticio de junio. Durante la PSSD el haz de luz que entra por la cúpula de San José no iluminó el pasillo pero empezó a desplazarse desde la parte inferior del muro trasero norte y avanzó luego hacia el altar (figura 14).

\section{IGLESIAS FUERA DE NORTEAMERICA: ECUADOR}

San Francisco, Quito, Ecuador (0¹3'12.91” S, 78³0'55.33” O). San Cristóbal (2000) comenta que la iglesia de Quito fue construida sobre las ruinas del Castillo Inca de Huayna Capac. Desde Google Earth podemos ver que esta orientada a $120^{\circ}$ acimuts, lo cual, seguramente no por casualidad, corresponde con una parada mayor de la luna, una alineación largamente observada en el Perú prehispánico (Adkins y Benfer 2009). San Cristóbal escribió que se dice que la iglesia recibe los rayos del sol del solsticio de diciembre sobre el volcán Cambaye situado al noreste, y los rayos del solsticio de junio de la iglesia sobre el Antisana situado al sudeste. Google Earth y Starry Night Pro con- 

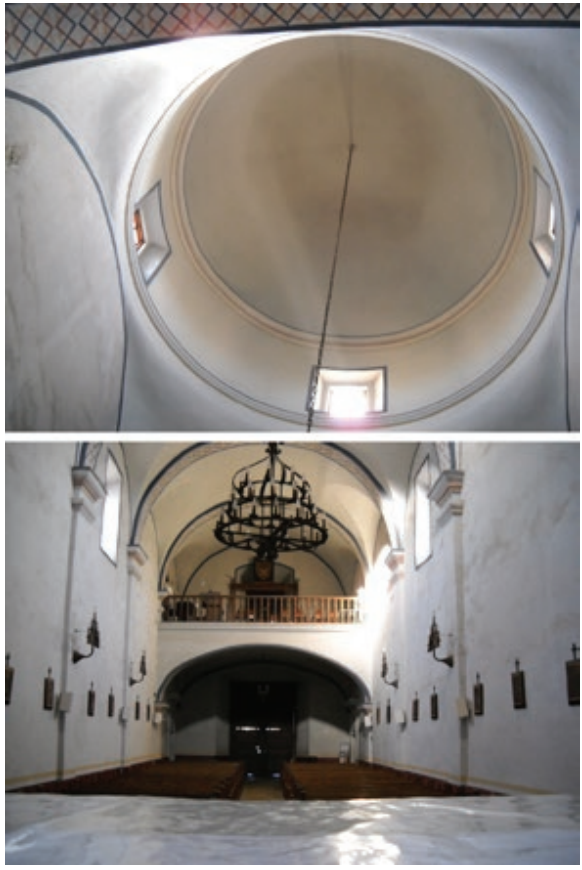

Figura 14-Mission San Jose, San Antonio, Texas, PSSD.

firman la alineación de la que habla San Francisco con el volcán Cambaye. El 21 de diciembre de 1534, a $2.3^{\circ}$ de elevación, la altitud del Cambaye desde la iglesia, el sol salió a 66 44'. Una línea desde San Francisco hasta la cima nevada del volcán sugiere unos $65^{\circ} 52^{\prime}$, dependiendo de dónde se ubique el punto de referencia.

Desafortunadamente, el alineamiento con el volcán Antisana no es igualmente plausible. Éste tiene un acimut de $125^{\circ}$ desde la iglesia. El 21 de junio de 1534 , a $3^{\circ}$ de altitud del volcán, el sol salió a $113^{\circ} 11^{\prime}$, bastante divergente de los $125^{\circ}$ esperados. Cristóbal reporta que el 22 de diciembre a las 09:00 am, la luz del sol sobre Antisana fue conducida a través de una de las torres de la iglesia para iluminar el altar con una luz brillante.

Es posible que Huayna Capac situara su palacio de forma que pudiera ver la salida del sol del solsticio sobre el Cambaye y que los españoles, colocando la iglesia sobre él, mantuvieran esa vista. Si pudiera ser confirmada la luz cayendo sobre el altar, ello querría decir que los colonizadores quisieron mantener la importancia astronómica de la posición del palacio de Huayna Capac, en la arquitectura de su iglesia. Claramente, esta importante iglesia merece una mayor investigación ya que podríamos estar ante la existencia de un observatorio pre-Inca debajo del templo. 


\section{IGLESIAS FUERA DE NORTEAMERICA Y ECUADOR: PERÚ}

En Lima varias iglesias sobrevivieron a sucesivos temblores y mantuvieron su orientación original. En este trabajo, hablaré sobre dos iglesias de Lima, San Pedro y la capilla de Veracruz (Figuras 15, 16, y 17).

San Pedro, Lima ( $12^{\circ} 2^{\prime} 57.59^{\prime \prime}$ S $77^{\circ} 1^{\prime}$ '43.02” O). La construcción de la iglesia jesuita de San Pedro, ahora Basílica, comenzó en 1568 DEC. Al igual que la cercana Catedral de Lima, la iglesia de San Pedro está orientada a $122^{\circ} 20^{\prime}$, así como las calles aledańas de la plaza de Armas. La figura 15 se ve la ventaba que hay sobre el altar desde dentro de la iglesia, un patrón similar al que se podría esperar en la iglesia de Santo Domingo en Chiapa de Corzo, Chiapas, México. Tomé esta foto el 15 de diciembre de 2010 , cuando el sol salía a $112^{\circ} 2^{\prime}$ a $50^{\circ} 13^{\prime}$ a las $10: 22$ AM. En 1568 , el sol salió en San Pedro el 14 de diciembre a $111^{\circ} 47^{\prime}$ a $47^{\circ} 44^{\prime}$ a las 10:22 AM.
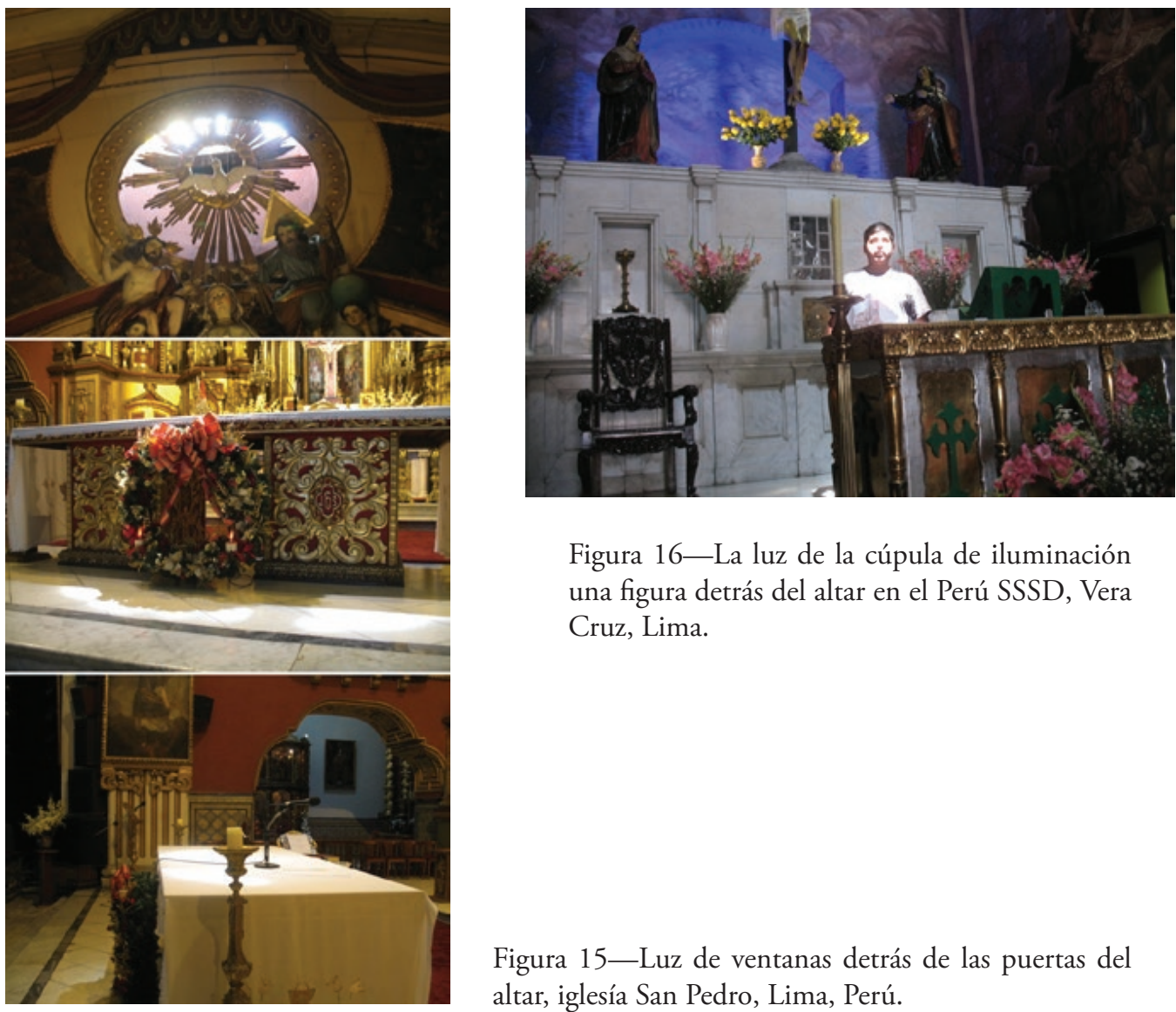

Figura 16-La luz de la cúpula de iluminación una figura detrás del altar en el Perú SSSD, Vera Cruz, Lima.

Figura 15-Luz de ventanas detrás de las puertas del altar, iglesía San Pedro, Lima, Perú. 
No pude estar lo suficientemente temprano allí, ni tuve posibilidad de permanecer más tiempo, ya que quería visitar otra iglesia cercana, por lo que me fue imposible determinar cuál fue el recorrido de la luz. Pero el cuidador me dijo que después de derramar un charco circular de luz sobre el altar, el rayo se dirigía hasta el retablo.

Veracruz, Lima $\left(12^{\circ} 2^{\prime} 38.16 ” S 77^{\circ} 2^{\prime} 11.88^{\prime \prime} \mathrm{O}\right)$. Esta iglesia fue fundada por Francisco Pizarro en 1535, es una capilla junto a San Sebastían, mucho más grande que aquélla pero establecida en el mismo año. Está a unas pocas cuadras de la iglesia de San Pedro y se alinea como ésta a $122^{\circ}$.

En la mañana de este mismo solsticio, una luz procedente de la cúpula ilumina a un hombre que accedió a posar para mí en el púlpito (Fig. 16). Uno puede imaginar que, sobre todo en el solsticio de diciembre, esta habría sido una visión inspiradora para la congregación.

Es sorprendente que el difundido fenómeno de la manipulación de la luz en las iglesias coloniales no haya sido conocido hasta hace poco. Evidentemente, se trataba de un conocimiento muy técnico de formas de construcción, pero su simbolismo es evidente cuando se observa el comportamiento de las luces. La orientación de las naves de las iglesias rurales hacia el solsticio puede ser otro patrón generalizado que sólo una investigación profunda puede establecer. Para quien no lleva una brújula, la orientación de las iglesias fácilmente puede pasar desapercibida y su significado puede no quedar muy claro.

Marcar los días del solsticio y del equinoccio pudo haber sido útil tanto para las creencias religiosas cristianas como para las indígenas. Sin embargo señalar los días de cruce de cuartos, como es el caso de Santo Domingo en SCLC, parece haber sido pensado especialmente para la parte indígena de la congregación. El señalamiento de las direcciones intercardinales de las iglesias y otros asentamientos debieron haber estado dirigidas a las necesidades espirituales de los pueblos indígenas; y el equinoccio habría servido a ambos pueblos. Este uso ceremonial de la luz no fue descubierto ni exclusivo de las iglesias cristianas, sino que es mucho más antiguo. Ya se conocen varios casos de este fenómeno prehispánico en Centroamérica y aquí yo presento dos casos del Perú que, al igual que los descubrimientos de las iglesias presentadas anteriormente, son recientes e inesperados.

Buena Vista, Lima, Perú (11\%43’52.15”S 7658’4.33” O). La manipulación de haces de luz para que sean proyectados sobre objetivos concretos y señalar el solsticio tiene al menos 4.000 años de antigüedad en las Américas. La figura 17 muestra una cámara especial en el sitio Precerámico Tardío de Buena Vista, Perú. La pared norte de esta cámara ha sido abierta a un ángulo mayor que la del sur para recibir los rayos del sol del solsticio (Benfer et al. 2010). La luz enmarca un nicho en una cámara construida en el año 2000 ANE. 


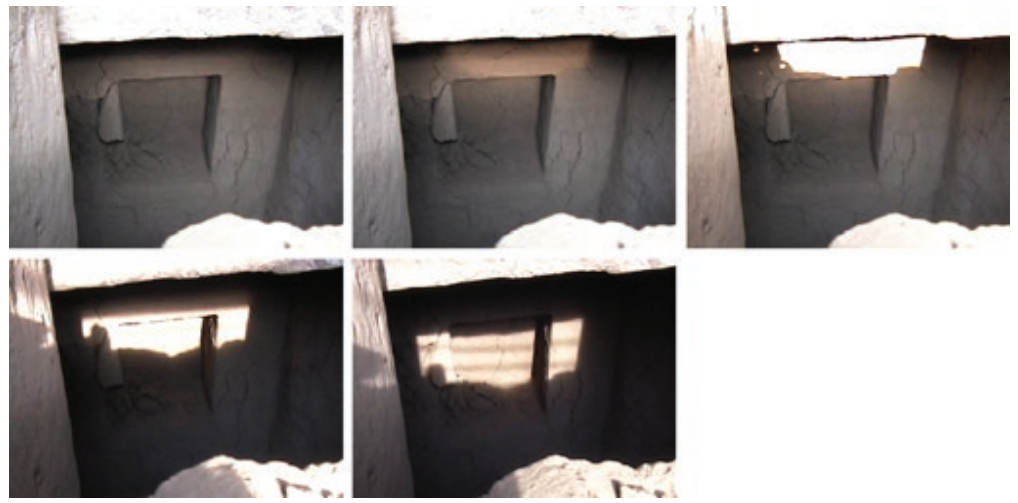

Figura 17-La luz de la iluminación DSSR un nicho en el sitio precereamico tardío de Buena Vista, Perú.

Una línea imaginaria que fuera desde la cámara de Buena Vista, Perú, de 2200 a. C, a través de una plataforma de piedra, trazaría el acimut de la puesta de sol del solsticio de diciembre. Otro línea terminaría en una mina de cuarzo (Fig. 18) que captura la puesta de sol del solsticio de junio casi en el centro de su apertura (Benfer et al. 2011). El acimut con declinación corregida observado el 19 de Diciembre del 2007 fue de 246 $09^{\prime}$ sobre una lejana cordillera a medio grado sobre la mina. El programa planetario Starry Night (V. 5.0.1) pronostica que el atardecer del 19 de diciembre del 2007 con un ajuste del horizonte de $0^{\circ} 5^{\prime}$, sería de $246^{\circ} 13^{\prime}$. Los clérigos-astrólogos y/o los mineros tuvieron que haber visto el atardecer en el solsticio en el año 2,000 BC a 245²3'. Debido a la oblicuidad, el atarceder prehistórico habría estado alrededor de medio grado del centro exacto de la salida de la mina (línea vertical de la figura 18).

Estos dos lugares, Buena Vista y Veracruz, están a menos de $40 \mathrm{~km}$ de distancia. En el valle de Casma del Perú, como se ha mencionado anteriormente, las calles del período colonial están orientadas a la salida del sol del solsticio de junio, al igual que los montículos prehispánicos del valle (Benfer et al. 2011) lo que sugiere que hubo una continuidad en las prácticas cosmológicas.

La manipulación humana de la luz del sol está muy extendida y es también muy antigua. Sin embargo, podría no ser una constante en las iglesias coloniales españolas fuera del Perú y Nueva España: una visita a Google Earth Pro a cuatro iglesias Patrimonio de la Humanidad en Filipinas no revela ningún patrón en cuanto a su orientación y menos aún, un patrón de tipo astronómico. Varias iglesias coloniales en Puerto Rico tampoco parecen tener una orientación astronómica clara en sus naves. Aunque no descartamos que las luces puedan haber sido dirigidas dentro de la iglesia en función de los días del solsticio y del equinoccio. A partir de esta investigación en su etapa inicial, sólo he hecho algunas generalizaciones tentativas sobre el uso ahora olvidado de la luz 


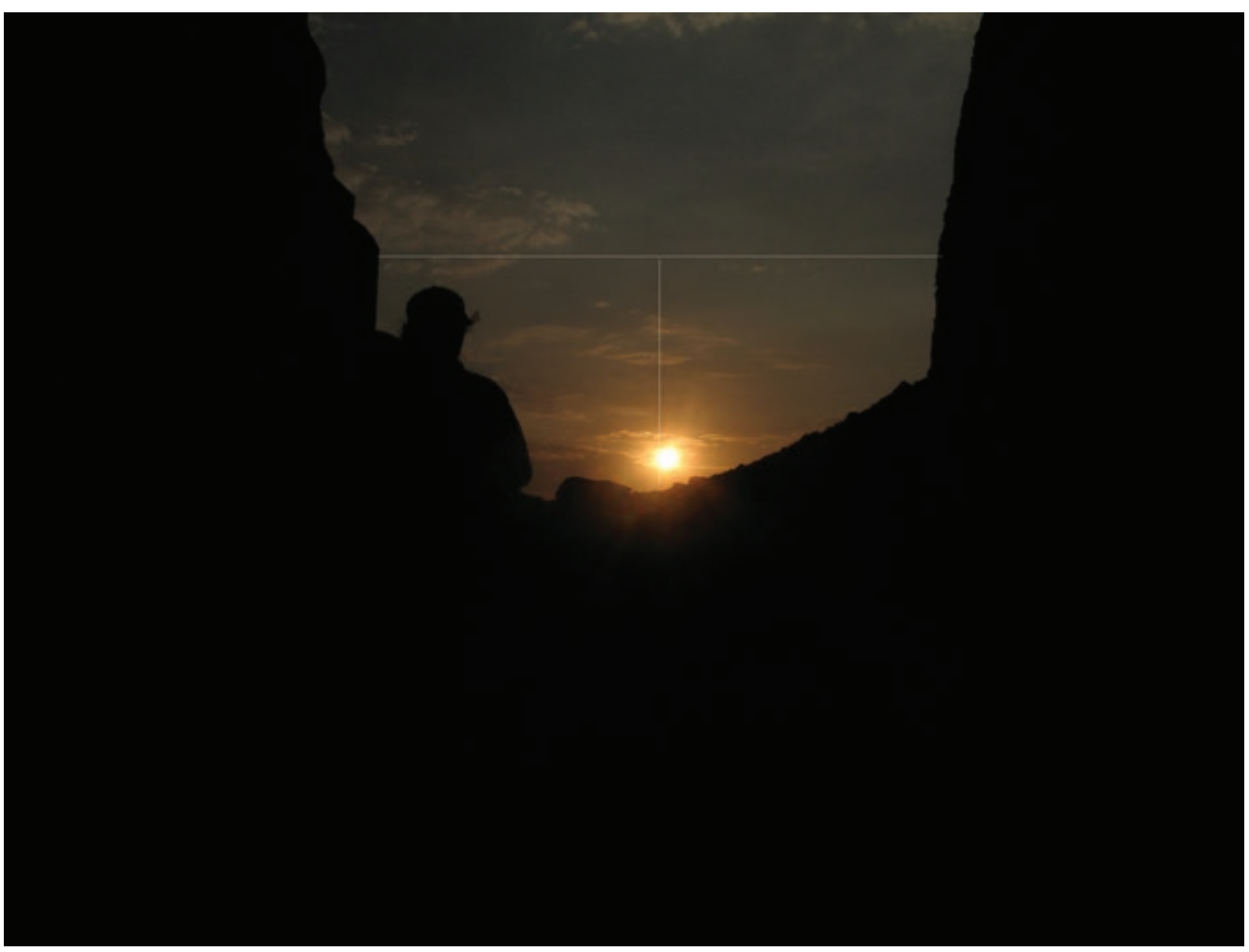

Figura 18 - Puesta de sol el 19 de diciembre de 2008, en la mina de cuarzo de Buena Vista.

dentro de las iglesias. Está claro que las luces y la orientación de la nave en las Iglesias Coloniales de las Américas marcan eventos importantes desde el punto de vista religioso y calendárico.

El uso de las luces de las ventanas laterales con el fin de iluminar puntos de interés dentro de las construcciones está muy extendido, especialmente en las iglesias que se abren hacia el Oeste. La iluminación del solsticio por la entrada sur puede representar un patrón, pero sólo se conocen dos casos, por lo que se requiere un estudio sobre más iglesias coloniales que tengan sus entradas hacia el sur. Un haz de luz que marca el día de cruce de cuartos puede observarse en las iglesias mayas pero, hasta ahora, sólo hay un ejemplo establecido y otro posible caso. En Chiapas, las naves de las iglesias indígenas rurales no suelen estar orientadas de Este-Oeste, sino sobre todo hacia el solsticio y hacia los amaneceres y puestas de sol de los puntos intercardinales. Futuros estudios mostrarán lo extendida que está la orientación de los campos de alrededor hacia los solsticios.

El conocimiento y el manejo de las luces prodentes de las ventanas se pudo haber perdido con el colapso del imperio español, aunque esto es sólo una conjetura. Los visi- 
tantes generalmente ni siquiera conocen la orientación de las naves y la mayoría de ellos suponen que éstas están de Este a Eeste. Hoy en día, sólo los que cuidan la iglesia y los niños se dan cuenta de estas luces (fig. 19).

\section{CONCLUSIONES}

Estos datos muestran que las iglesias y las misiones coloniales fueron comúnmente orientadas hacia direcciones de interés astronómico, de Este a Oeste (para muchas de las iglesias urbanas) y hacia el solsticio para muchas de las rurales. El descubrimiento de construcciones alineadas hacia el solsticio es un misterio para los católicos de hoy día, ya que esperan que la orientación esté marcada por el equinoccio de invierno, asociado con la Pascua. En cualquier caso, algunas de las iglesias cristianas más antiguas que han sobrevivido, como la de Santa Sofía en Estambul, están orientadas hacia el solsticio. La hipótesis de que las iglesias rurales están orientadas hacia el solsticio para acercarse a las creencias locales es válida, pero también sería posible que dicha alineación tuviera relación con la vieja tradición Católica.

Las iglesias suelen seguir la dirección de los planos de las ciudades coloniales; pero, incluyo si la iglesia es destruída, como en el caso de Casma, Perú, la orientación de las viejas ciudades hacia el solsticio permanece. La irregularidad de los patrones cosmológicos seguidos por los tempranos arquitectos espańoles puede verse en casos como Arequipa, Perú, una ciudad situada en el extremo opuesto del país cuya iglesia sigue la alineación del solsticio de diciembre en lugar del de junio.

Uno de los descubrimientos más curiosos que he tenido fue la orientación de algunas iglesias a $300^{\circ}$, para lo cual no tengo una explicación.

Los hallazgos expuestos aquí confirman el redescubrimiento inicial de Mendoza sobre el sofisticado uso de los rayos de luz en las misiones coloniales de California. Es asombroso que las iglesias y misiones de California, en los Estados Unidos, Chiapas, en México y Lima, Perú, muestren la misma destreza de los arquitectos en la manipulación de la luz.

A pesar de los retos, los arquitectos de la época colonial fueron capaces de diseñar iglesias, cada una con una altura diferente en su cúpula, colocación de las ventanas y orientación para producir rayos de luz que trazaran el camino del pasillo o dirigidos hacia el púlpito o la entrada sur de la nave o cualquier otro punto de interés. Los arquitectos no habrían sabido cómo iba a estar amueblada la iglesia, pero sí sabían que el pasillo debía estar debajo del eje central de la construcción y también cómo estaba diseñada la localización de las puertas y las ventanas. 
Los rayos de luz procedentes de las ventanas de la cúpula que marcan el equinoccio, el solsticio y los días de cruce de cuartos en algunas iglesias de la época de la colonia española. Pero en estas iglesias también puede haber proyecciones de luz provenientes de las ventanas laterales así como de las ventanas del final de la nave. En junio del año 2012 estuve en Ljubliana, Eslovenia, para la conferencia de la Sociedad Europea de Arqueoastronomía. Visité una vieja iglesia de la Anunciación cinco días antes y dos días después del equinoccio. La iglesia está orientada casi exactamente de norte a sur. El 22 de junio, un rayo de luz procedente de una ventana del oeste iluminó una estructura en forma de cúpula con una cruz en lo alto que hay sobre el altar. Pero los astrónomos que están comenzando a estudiar las orientaciones de las iglesias en Eslovenia no conocían este caso.

Antes de los descubrimientos de Mendoza, no había reporte alguno que diera a conocer semejante manejo de la luz en las iglesias del Nuevo Mundo. Markman (1985) quien escribió un libro sobre la arquitectura colonial de Chiapas, no encontró nada al respecto ni se percató de este fenómeno en las mismas iglesias. Pero, en cualquier caso, una nueva investigación de archivo estaría justificada ya que seguramente debe haber alguna mención.

Una breve investigación a través de Google Earth en el caribe que fue colonia española y en las Islas Filipinas no reveló otra orientación astronómica de las iglesias que no fuera hacia el equinoccio. Otra breve investigación en América Central reveló algunas iglesias como Santo Tomás en Chichicastenango con una orientación hacía el solsticio que marca el día de Santo Tomás. El fenómeno debe reducirse a la América continental. Hasta aquí, no se han econtrado ejemplos de este fenómeno de manipulación de la luz en amaneceres o atardeceres de importancia astronómica que no estuveran dentro de la época de la Colonia Española en América. No obstante esta generalización está basada tan sólo en unas cuantas iglesias.

Es posible que el conocimiento de los clérigos-arquitectos se perdiera durante el caótico momento de las revoluciones. O posiblemente era el momento en que los científicos han terminando haciendo perforaciones en las iglesias de Europa. Hoy día la razón de la pérdida de este conocimiento es un misterio. Ni los fieles ni los clérigos entienden el significado que le dieron a estas luces los antiguos arquitectos. Sin embargo, cumpliendo la intención para la que fueron diseñados, estos juegos de luces continúan apareciendo año tras año. Si se comprendiera la belleza de estos rayos de luz, ello contribuiría a la trascendencia de las ceremonias que ocurran mientras los rayos de luz atraviesan lentamente la iglesia marcando los cíclicos cambios de la tierra. En la figura 19 podemos ver a los niños jugando con un rayo de luz que se desvanece después de haber trazado el Meridiano a lo largo del pasillo de la iglesia de Santo Domingo en San Cristóbal de las Casas y que se desvanecerá después de pasar por el púlpito. 
Figura 19-Los niños que bailaban en el rayo de luz desde la cúpula en el equinoccio de Santo Domingo, Chiapas, México.

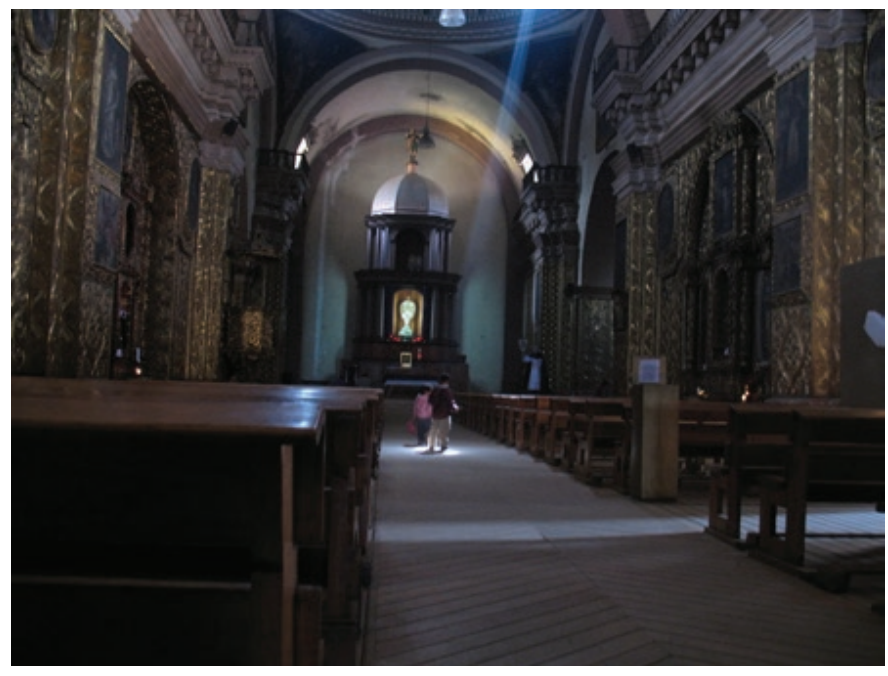

Agradecimientos: A Thomas A. Lee, recientemente fallecido, quien me llevó a varias de las misiones abandonadas y me ofreció siempre orientaciones muy valiosas. A Monica Barnes por sus siempre útiles críticas y sus fuentes. A mi padre, quien me llevó a las misiones de San Antonio en varias ocasiones. A María Cruz La Chica Delgado que ha traducido este informe.

\section{REFERENCIAS CITADAS}

Amson, John Ceres 2008 Gregory's meridian line of 1673-74: A St. Andrews detective story, Journal of the British Society for the History of Mathematics: 23: 58-72.

Adkins, Larry R. and Robert A. Benfer 2009 Lunar Standstill Markers at Preceramic Temples at the Buena Vista Site in Perú. Astronomical Society of the Pacific Conference Series: 409: 267-278.

Aveni, Anthony and Horst Hartung 1986 Maya City Planning and the Calendar. Transactions of the American Philosophical Society, Vol. 76, Part 7.

Anonymous Catálogo Nacional de Monumentos Históricos Inmuebles, Vol. VI. (CONACULTA INAH, Estado de Chiapas, Mexico, 1999).

Benfer, Robert A., Bernardino Ojeda, Neil A. Duncan, Larry R. Adkins, Hugo Ludeña, Miriam Vallejos, Víctor Rojas, Andrés Ocas, Omar Ventocilla y Gloria Villarreal 2010 La Tradición Religioso-Astronómica en Buena Vista. Boletín de Arqueología PUCP 11: 53-102. 
Anaya Avila, María del Pilar, Patricia del Carmen Aguirre Gamboa2, Rossy Lorena Laurencio Meza y Anaya Avila, Maria del Pilar, Patricia del CarmenAguirre Gamboa, Rossy Lorena Laurencio Meza, and María del Rocío. and Ojeda Callado 2010. La enseñanza de la redacción periodística y las competencias tecnológicas que requieren los alumnos de Comunicación de la Universidad Veracruzana. Congreso Internacional de AcademiaJournals.com, ISSN 1946-5351 Online.

Atigas, Juan B. 1991 La Arquitecutra de San Christóbal de las Casas. Gobierno del Estado de Chiapas, UNAM.

Benavides, Antonio 1984 La arqueología histórica Maya de Chiapas: un inicio. XVII Mesa Redonda de la Sociedad Mexicana de Antropología, II: 195205. Mexico.

Castañeda, Carlos E. 1940 The Beginning of Printing in America The Hispanic American Historical Review, 20: 671-685.

Casistor, Nick 2009 Mexico City. Oxford: Signal.

Cuesta Hernández, Luis Javier 2009 Arquitecture del Renacimiento en Nueva Espańa. Universidad Iberoamericana Ciudad de México.

Dawson, George M. 2004 Sunsets at Mission Concepción: Pursuit of a Legend. Manuscript.

Evans, Robin 1995 The Projective Cast: Architecture and Its Three Geometries (MIT Press).

Fisher, Lewis F. 1998. The Spanish Missions of San Antonio. Maverick Press.

Furbee, Louanna 2011 The World's Water: Seasons and Mayan Cosmology in Present-Day Chiapas. Paper presented in the Symposium on Traces, Tidemarks and Legacies of Change and Difference in Maya Sprirituality. American Anthropological Association, November 17, 2011, Montreal, Canada.

Furbee, Louanna 2013 Ethnography in Support of Archaeoastronomy: The Meaning of Tojolab'al Maya Mountain Alignments IN Ancient Cosmologies and Modern Prophets: Proceedings of the 20th Conference of the European Society for Astronomy in Culture, Edited by Ivan Šprajc and Peter Pehani. Anthropological Notebooks XIX, Supplement, pp. 277-286.

Gossen, Gary 1999 Telling Maya Tales: Tzotzil Identities in Modern Mexico. New York: Routledge. 
Heyd, Michael 2003 The Discourse of Pious Science, Cambridge University Press Online Journals, 16.

Heilbron, J.L. 1999 The Sun in the Church: Cathedrals as Solar Observatories (Cambridge Mass: Harvard University Press).

Lee, Thomas Arvol and Sidney D. Markman 1977 The Coxoh Colonial Project and Coneta, Chiapas, Mexicco: A Provincial Maya Village under the Spanish Conquest. Historical Archaeology, Vol. II, pp. 56-66. Society for Historical Archaeology.

McClusky, S. 2007. Calendrical Cycles, the Eighth Day of the World, and the Orientation of English Churches IN C. Ruggles and G. Urton (eds), Skywatching in the Ancient World: New Perspectives in Cultural Astronomy. Studies in Honour of Anthony F. Aveni, Boulder, Colorado: University of Colorado Press, pp. 331-353.

Markman, Sidney 1984 Architecture and Urbanization in Colonial Chiapas, Mexico. Philadelphia, American Philosophical Society

Mendoza, Rubén G. 2005 Sacrament of the Sun: Eschatological Architecture and Solar Geometry in a California Mission. 22, 87-110, The Jounal of the California Mission Studies Association.

Mendoza, Rubén 2009 Presidio Light: A Midwinter Sosltice Event at the Presidio Chapel of Santa Bárbara, Fall, 4-11.

Milbrath, Susan 1999. Star Gods of the Maya: Astronomy in Art, Folklore, and Calendars. Austin, University of Texas Press.

Newsome, Elizabeth A. Trees of Paradise and Pillars of the World: The Serial Stela Cycle of «18-Rabbit-God K,» King of Copan. Austin, University of Texas Press.

Ortiz Herrera, Rocío 2003 Pueblos Indios, Iglesia Católica y Élites Políticas en Chiapas (1824-1901). Una perspectiva comparativa. CONECULTA-El Colegio de Michoacán.

Peraza Guzmán, Marco 2000 Arquitecturea y urbanismo virreinal (Coordinador), Univeridad Autónoma de Yucatán, Facultad de Arquitectura.

Rice, Prudence M. 2005 Maya Calendar Origins: Monuments, Mythistory, and the Materialization of Time. UT Press.

San Cristobal, Antonio 2000 Estructuras ornamentals de la arquitectura virreinal Peruana. Lima, Universidad Nacional de Ingeniería. 
Schibille, Nadine 2009 Astronomical and Optical Principles in the Architecture of Hagia Sophia in Constantinople, Science in Context 22: 27-46.

Tomka, Steve A. , Anne A. Fox, Barbara Meissner - 1999 Mission San José, San Antonio, Texas. Archaeological Survey Report, No. 287. Center for Archaeological Research, The University of Texas at San Antonio. 